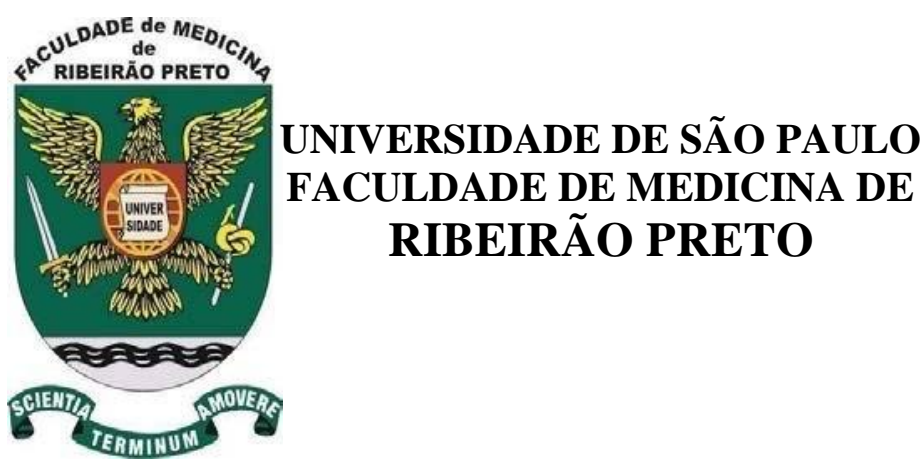

INFLUÊNCIA DA QUEIMADURA CUTÂNEA DE TRONCO, NA FASE CRÔNICA, NA FUNÇÃO PULMONAR E MUSCULAR RESPIRATÓRIA EM INDIVÍDUOS TABAGISTAS
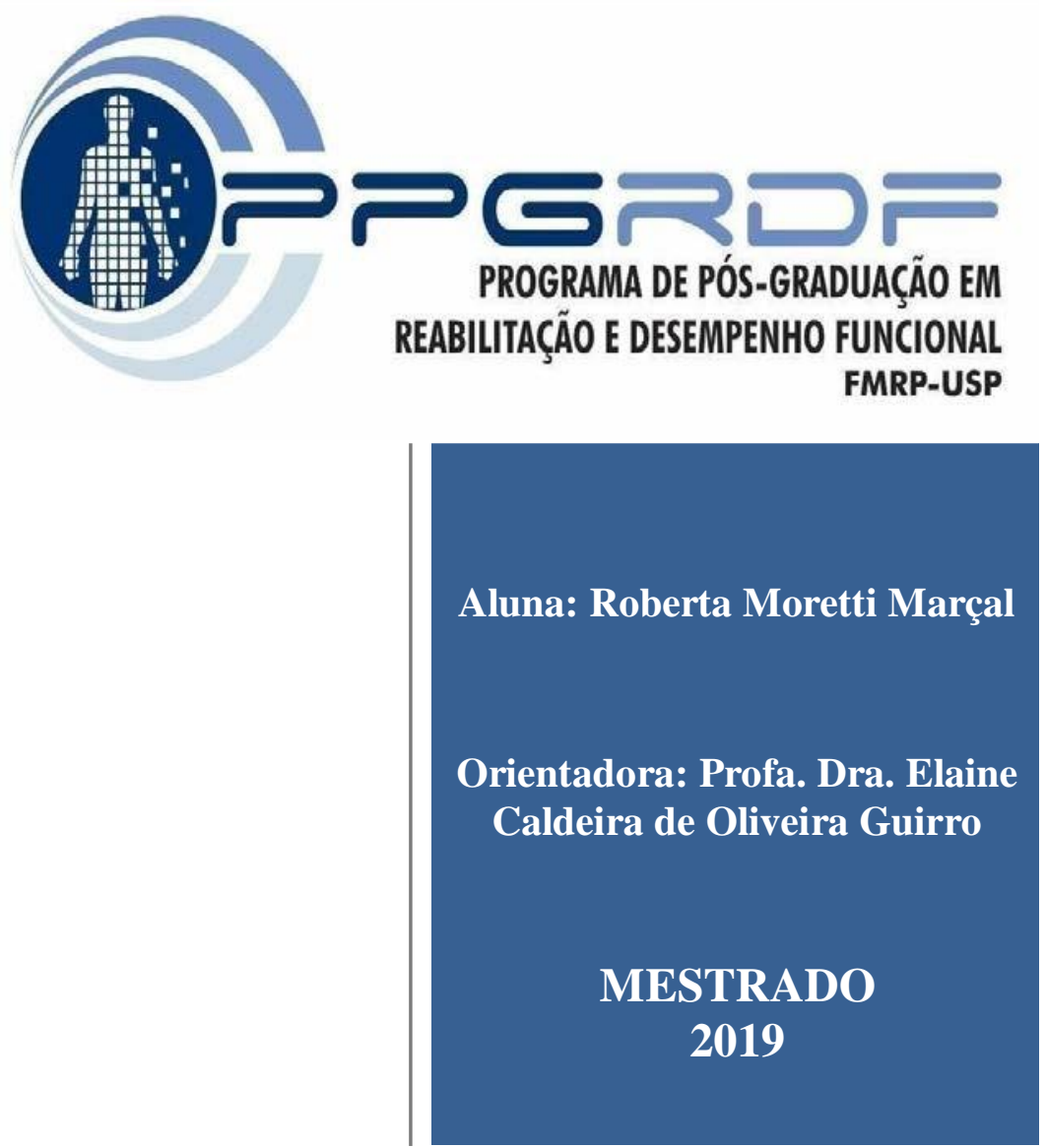


\author{
UNIVERSIDADE DE SÃO PAULO \\ FACULDADE DE MEDICINA DE RIBEIRÃO PRETO
}

ROBERTA MORETTI MARÇAL

Influência da queimadura cutânea de tronco na fase crônica, na função pulmonar e muscular respiratória em indivíduos tabagistas. 
ROBERTA MORETTI MARÇAL

\title{
Influência da queimadura cutânea de tronco na fase crônica, na função pulmonar e muscular respiratória em indivíduos tabagistas.
}

\author{
Versão corrigida. \\ A versão original encontra-se disponível tanto \\ na Biblioteca da Unidade que aloja o Programa, quanto \\ na Biblioteca Digital de Teses e Dissertações da USP (BDTD).
}

Dissertação apresentada ao Programa de Pós- Graduação em Reabilitação e Desempenho Funcional - FMRP/USP, pelo Departamento de Biomecânica, Medicina e Reabilitação do Aparelho Locomotor para obtenção do Título de Mestre em Ciências.

Área de concentração: Fisioterapia

Orientadora: Profa. Dra. Elaine Caldeira de Oliveira Guirro 
Autorizo a reprodução e divulgação total ou parcial deste trabalho, por qualquer meio convencional ou eletrônico, para fins de estudo e pesquisa, desde que citada a fonte.

Catalogação da Publicação

Serviço de Documentação da Faculdade de Medicina Faculdade de Medicina de Ribeirão Preto da Universidade de São Paulo

Marçal, Roberta Moretti

Influência da queimadura cutânea de tronco na fase crônica, na função pulmonar e muscular respiratória em indivíduos tabagistas. Ribeirão Preto, 2019.

74 p. : il. ; $30 \mathrm{~cm}$

Dissertação de Mestrado, apresentada à Faculdade de Medicina de Ribeirão Preto/USP. Área de concentração: Fisioterapia.

Orientadora: Guirro, Elaine Caldeira de Oliveira.

1. Fisioterapia. 2. Queimadura. 3. Maleabilidade. 4. Mecânica respiratória. 
Nome: Roberta Moretti Marçal

Título: Influência da queimadura cutânea de tronco, na fase crônica, na função pulmonar e muscular respiratória em indivíduos tabagistas.

Dissertação apresentado ao programa de Pós-Graduação em Reabilitação e Desempenho Funcional - FMRP/USP para obtenção do Título de Mestre em Ciências.

Área de concentração: Fisioterapia

Aprovado em:

Banca Examinadora

Prof ${ }^{\mathrm{a}} . \mathrm{Dr}^{\mathrm{a}}$. Instituição:

Julgamento: Assinatura:

Prof ${ }^{\mathrm{a}} . \mathrm{Dr}^{\mathrm{a}}$.: Instituição:

Julgamento: Assinatura:

Prof ${ }^{\mathrm{a}} . \mathrm{Dr}^{\mathrm{a}} .:$ Instituição:

Julgamento: Assinatura: 
DEDICATÓRIA 
Dedico este trabalho à minha estimada irmã, Rosilene Moretti Marçal (in memoriam), por mostrar incansavelmente desde a minha tenra idade, à importância do estudo. 
AGRADECIMENTOS 


\section{AGRADECIMENTOS}

Agradeço à Deus que se faz presente na vida por meio das pessoas, seja em momentos felizes ou em momentos difícies quando somos recebidos de braços abertos e que nos estendem as mãos em momentos cruciais e nos traz à tona novamente.

A Profa. Dra. Elaine Caldeira de Oliveira Guirro por toda dedicação, transmissão de conhecimentos e pela paciência nessa jornada. Muito obrigada por contribuir para o meu crescimento pessoal e profissional. Serei sempre grata Professora, levarei seu sorriso pela estrada a ser percorrida.

Aos meus pais Roseli e Antônio (in memoriam) por me proporcionarem à vida.

Aos meus amados avós Antônio Marçal (in memoriam) e Dulce de Souza Marçal (in memoriam) por todos os esforços aplicados à mim e aos meus irmãos, Rosilene, Renata, Antônio e Alexandre, que sempre empenharam-se para educar e formar todos nós, meus mais sinceros sentimentos.

A minha irmã Rosilene que me auxílio nessa trajetória, mas que não foi possível estar aqui hoje em presença, mas estamos sempre unidas pelos laços do espírito.

As minhas filhas Victória e Olivia que foram, são e sempre serão a razão da minha vida.

A Profa. Dra. Adriana Gonçalves por todo ensinamento, amor, paciência, amizade, pelos momentos felizes e difíceis que sempre compartilhamos, minha eterna gratidão.

Agradeço a Rosane Castaldelli, Maria S. Ferreira, Aparecida C. Botelho e Carmen L. de Souza, do Centro de Estudos da Unidade de Emergência - Unidade de emergência do Hospital das clínicas de Ribeirão Preto, pela disponibilidade que sempre me acolhem e contribuíram em todos os momentos dessa trajetória. Muito obrigada!

A Profa. Dra. Suzelei de Castro França (Universidade de Ribeirão Preto), que me incentivou com toda sua delicadeza e docilidade, à prosseguir nos estudos. 
A banca de qualificação composta pelos professores Dr. Prof. Pedro Soler Coutro e Dr. Paulo Ferreira, pela leitura crítica e pelas sugestões oferecidas.

Ao Prof. Dr. Rinaldo Roberto de Jesus Guirro que acompanhou todo o processo nesses dois anos e aos meus colegas dos laboratórios LAIDEF, LARF E LAR pelos conhecimentos compartilhados.

A Jéssica Silva que com muita determinação participou de todo o processo desse trabalho, muito obrigada!

A equipe multiprofissional da Unidade de Queimados - Unidade de emergência do Hospital das clínicas de Ribeirão Preto, pela qual fui acolhida desde o início das minhas atividades profissionais e sempre estiveram presentes no dia a dia. Serei sempre grata à essa equipe!

Agradeço a todos os colaboradores do Programa de Reabilitação e desempenho funcional, Samuel Filipine, Marília Prioli, Edvaldo Gonçalves, pela disponibilidade.

Agradeço o programa de Pós-Graduação e Desempenho Funcional, a Faculdade de Medicina de Ribeirão Preto e a Universidade de São Paulo.

Agradeço a Coordenação de Aperfeiçoamento de Pessoal de Nível Superior (CAPES) pelo apoio financeiro.

Aos participantes da pesquisa que aceitaram esse desafio com boa vontade, paciência e pensando no bem comum "das próximas vítimas de queimaduras", sem os quais não seria possível prosseguir com essa pesquisa. Que Deus ilumine e proteja o caminho de cada um de vocês! 
“Há um tempo em que é preciso abandonar as roupas usadas, que já tem a forma do nosso corpo, e esquecer os nossos caminhos, que nos levam sempre aos mesmos lugares. É o tempo da travessia: e, se não ousarmos fazê-la, teremos ficado, para sempre, à margem de nós mesmos."

(George Bernard Shaw) 


\section{RESUMO}

Marçal, R. M. Influência da queimadura cutânea de tronco, na fase crônica, na função pulmonar e muscular respiratória em indivíduos tabagistas. 2019. 72 f. Dissertação (Mestrado) Faculdade de Medicina de Ribeirão Preto, Universidade de São Paulo, Ribeirão Preto, 2019.

As cicatrizes de tronco na fase crônica, podem afetar a função pulmonar, pela dor, extensão, bem como maleabilidade comprometida. O objetivo deste estudo foi avaliar a influência da cicatriz de tronco, fase crônica, na função pulmonar e muscular respiratória em indivíduos tabagistas e não tabagistas. Foram avaliados 40 indivíduos com média de idade $37.82( \pm 0.83)$ anos de ambos os sexos, com queimadura de segundo grau profundo e terceiro grau na região do tronco, divididos em dois grupos: indivíduos tabagistas na fase crônica (20) com média de idade 41.45 ( \pm 11.09$)$ anos, indivíduos não tabagistas fase crônica (20) com médiade idade 34.2( \pm 10.57$)$ anos. Foram avaliadas as características biomecânicas da pele (maleabilidade e firmeza), frequência não paramétrica que permite à comparação respiratória (FR),volume corrente (VC), volume minuto (VM),força muscular inspiratória (PImáx), força muscular expiratória (PEmáx). Para análise estatística inicialmente os dados foram descritos através de frequências absolutas e percentuais, com de medidas como média, desvio-padrão, mínimo, média e máximo. A comparação dos grupos foi feita por meio do teste de Mann-Whitney. Para as comparações do impacto das queimaduras entre os grupos, foi proposta a análise de covariância (ANCOVA), que além de comparar grupos ,permite o ajuste de covariáveis. Todos os modelos foram ajustados por sexo e idade, e as análises foram efetuadas pelo pacote estatístico SAS9.2, e para todas as comparações adotou-se um nível de significância de 5\%. Resultados: Não foram encontradas diferenças significativas em relação a função pulmonar, bem como nas características biomecânicas da cicatriz crônica de pele de indivíduos queimados tabagistas e não tabagistas. Conclusão: Não foram encontradas diferenças significativas entre indivíduos tabagistas e não tabagistas nos parâmetros respiratórios e biomecânicos da pele na população avaliada.

Palavras-chave: Fisioterapia; Queimaduras; Maleabilidade; Mecânica Respiratória. 


\begin{abstract}
Marçal, R. M. Influence of cutaneous burn in the chronic phase, respiratory pulmonary and muscular function in smoking individuals. 2019. $72 \mathrm{f}$. Dissertation (Master) - Medicine School of Ribeirão Preto, University of São Paulo, Ribeirão Preto, 2019.

Chronic trunk scarring can affect lung function by pain, extension as well as impaired malleability. The aim of this study was to evaluate the influence of trunk scarring, chronic phase, on pulmonary and respiratory muscle function in smokers and non-smokers. Forty individuals with a mean age of $37.82( \pm 0.83)$, years of both sexes, with deep second degree burn and third degree in the trunk region, were divided into two groups: individuals with chronic age (20) with average age.41.45 $( \pm 11.09)$ years, non-smokers chronic phase $(20)$ with mean age $34.2( \pm$ 10.57) years. The biomechanical characteristics of the skin (malleability and firmness), nonparametric frequency allowing the respiratory comparison (RR), tidal volume (TV), minute volume (MV), inspiratory muscle strength (MIP), expiratory muscle strength (MEP) were evaluated. For statistical analysis, data were initially described as absolute frequencies and percentages, with measures such as mean, standard deviation, minimum, mean and maximum. The groups were compared by the Mann- Whitney test. For comparisons of the impact of torso burn between the groups, the covariance analysis (ANCOVA) was proposed, which besides comparing groups, allows the adjustment of covariates. All models were adjusted for gender and age, and analyzes were performed using the SAS 9.2 statistical package, and for all comparisons a significance level of 5\% was adopted. Results: No significant differences were found regarding lung function, as well as biomechanical characteristics of chronic skin scarring of smokers and on- smokers. Conclusion: No significant differences were found between smokers and non-smokers in the respiratory and biomechanical parameters of the skin in the evaluated population
\end{abstract}

Keywords: Physical Therapy; Burns; Malleability; Respiratory Mechanics. 


\section{LISTA DE FIGURAS}

Figura 1 - Imagem ilustrativa da coleta com o aparelho Durometer...................................29

Figura 2 - Imagem ilustrativa da coleta com o aparelho Cutômetro.......................................30

Figura 3 - Imagem ilustrativa do instrumento trena Antropométrica .................................... 31

Figura 4 - Imagem ilustrativa da coleta com o aparelho Manovacuômetro. ..........................32

Figura 5 - Imagem ilustrativa da coleta com o equipamento Ventilômetro ..........................33 


\section{LISTA DE TABELAS}

Tabela 1 - Características físicas dos pacientes estudados.................................. $\quad 35$

Tabela 2 - Descrição do local do acidente............................................................. 36

Tabela 3 - Valores referentes ao agente causador da queimadura.......................... 36

Tabela 4 - Valores referentes ao padrão respiratório dos pacientes analisados

Tabela 5 - Valores referentes a análise de dor dos pacientes analisados durante a realização técnica da cirtometria

Tabela 6 - Valores referentes aos parâmetros respiratórios, pressão inspiratória máxima e pressão expiratória máxima dos pacientes avaliados

Tabela 7 - Valores referentes a variável dependente PImáx e valores das variáveis independentes

Tabela 8 - Valores referentes aos parâmetros respiratórios, PEmáx dos pacientes avaliados.

Tabela 9 - Valores referentes a variável dependente PEmáx e valores das variáveis independentes.

Tabela 10 - Valores referentes a variável dependente cirtometria axilar inicial e valores das variáveis independentes

Tabela 11 - Valores referentes a variável dependente cirtometria axilar inspiratória e valores das variáveis independentes

Tabela 12 - Valores referentes a variável dependente cirtometria axilar expiratória e valores das variáveis independentes

Tabela 13 - Valores referentes a variável dependente cirtometria xifoide inicial e valores das variáveis independentes.

Tabela 14 - Valores referentes a variável dependente cirtometria xifoide inspiratória e valores das variáveis independentes

Tabela 15 - Valores referentes a variável dependente cirtometria xifoide expiratória e valores das variáveis independentes

Tabela 16 - Valores referentes a variável dependente cirtometria umbilical inicial e valores das variáveis independentes. 
Tabela 17 - Valores referentes a variável dependente cirtometria umbilical inspiratória e valores das variáveis independentes.

Tabela 18 - Valores referentes a variável dependente cirtometria umbilical expiratória e valores das variáveis independentes.

Tabela 19 - Valores referentes a variável dependente volume minuto e valores das variáveis independentes.

Tabela 20 - Valores referentes a variável dependente volume corrente e valores das variáveis independentes.

Tabela 21 - Valores referentes à avaliação dos parâmetros de elasticidade e rigidez de tecidos cicatrizados nas regiões controle, $2^{\circ}$ profundo, enxertada, da média controle, média $2^{\circ}$ profundo e média enxertada.

Tabela 22 - Comparação entre os grupos (teste de Mann-Whitney) 


\section{LISTA DE SIGLAS}

DP Desvio padrão

EVA Escala Numérica de Avaliação de Dor

F Feminino

FR Frequência Respiratória

I.P.M Incursões por Minuto

IMC Índice de Massa Corpórea

M Masculino

PEMÁX Pressão Expiratória Máxima

PIMÁX Pressão Inspiratória Máxima

\% SCQ Porcentagem de Superfície Corpórea Queimada

VC Volume Corrente

VM Volume Minuto 


\section{SUMÁRIO}

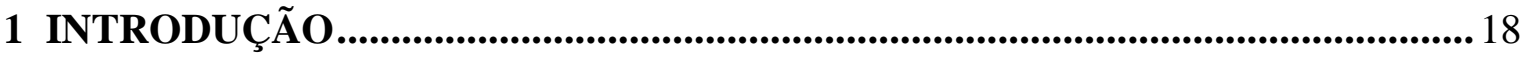

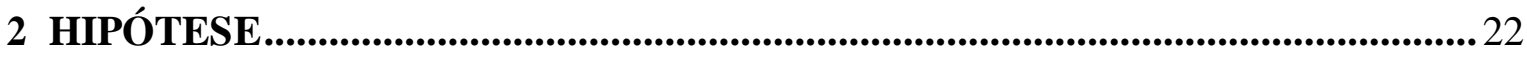

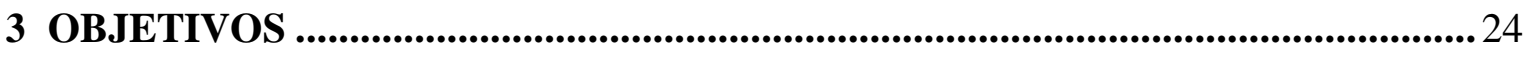

3.1 Objetivo geral ............................................................................................................. 24

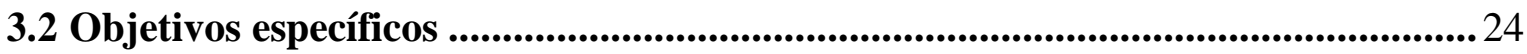

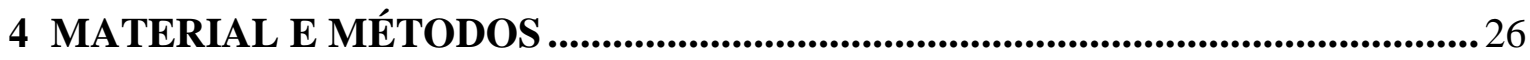

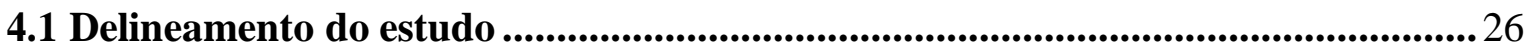

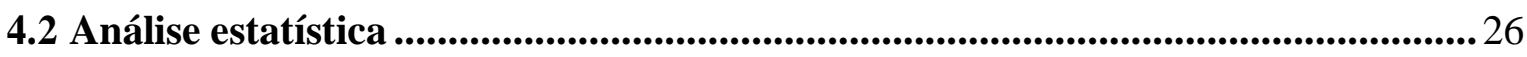

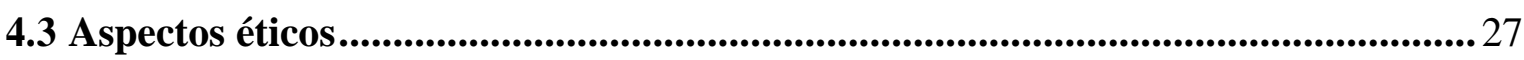

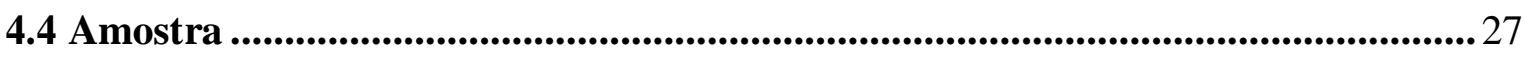

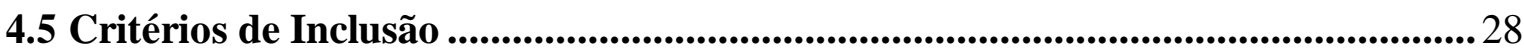

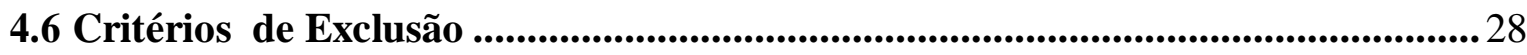

4.7 Ficha de Avaliação Respiratória no Paciente Queimado ......................................... 28

4.8 Avaliação das propriedades Biomecânicas da Pele ................................................. 28

4.9 Avaliação da Função Respiratória .................................................................. 30

4.9.1 Avaliação da Expansibilidade Torácica.................................................................... 30

4.9.2 Avaliação da Força Muscular Respiratória ....................................................... 31

4.9.3 Avaliação da mecânica respiratória............................................................. 32

4.9.4 Avaliação da dor..................................................................................................... 33

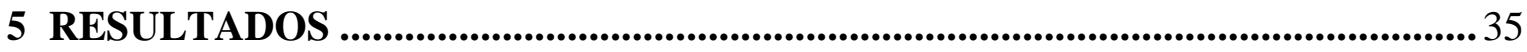

5.1 Caracterização física e social do grupo emestudo........................................... 35

5.2 Avaliações da influência da queimadura sobre parâmetros respiratórios...... 37

5.3 Resultados referentes às avaliações da influência da queimadura sobre a elasticidade e rigidez dos tecidos cicatrizados................................................ $\quad 45$

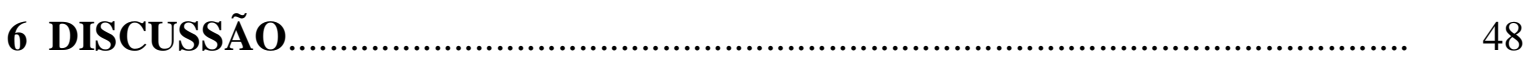

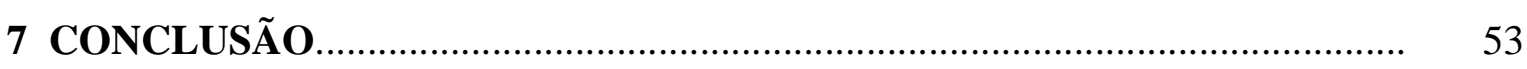

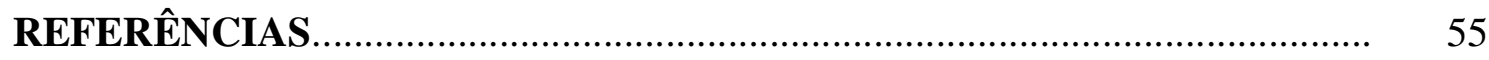

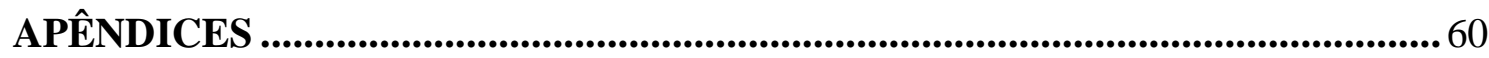

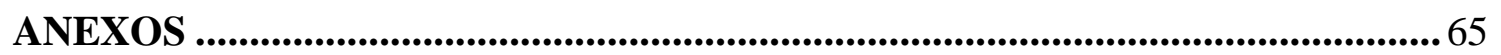


INTRODUÇÃO 


\section{INTRODUÇÃO}

As queimaduras de tronco podem produzir comprometimento respiratório restritivo significativo, por afetar diretamente o sistema respiratório ou pelas cicatrizes desenvolvidas na região, dificultando a expansibilidade torácica. No entanto, o envolvimento das sequelas na pele, tratadas com enxertias, relacionadas à restrição de expansibilidade é pouco estudado (Angrigiani et al., 2015).

A associação entre a cicatrização de feridas e o tabagismo tem sido investigada, contudo, estudos relacionando os efeitos associados a queimaduras são escassos (Siana; Rex, 1989; Silvertein, 1992).

A nicotina é o componente mais ativo no tabaco, e acarreta um efeito vasoativo limitado na pele e tecido subcutâneo. Essa alteração claramente reduz o fluxo sanguíneo do tecido, comprometendo o metabolismo aeróbio (Pluvy et al., 2015). É caracterizada como principal causadora de complicações pós-operatórias em feridas em indivíduos fumantes (Cavichio et al 2014; Xanthoulea et al., 2013; Dinos et al., 2015; Pluvy et al., 2015).

A atividade metabólica inicial depende da proporção de superfície corpórea queimada (SCQ), assim como, a profundidade da queimadura, sexo, e faixa etária que são fortes indicativos da gravidade da lesão, e mantém uma estreita relação com a mortalidade do paciente. Após grandes queimaduras verifica-se uma resposta hipermetabólica e consequentemente hiperdinâmica, com o aumento da temperatura corporal, do consumo de glicose e de oxigênio, aumento da formação de CO2, glicogenólise, lipólise e proteólise (Jewo et al., 2006).

A necessidade de uma demanda aumentada de oxigênio no indivíduo queimado exige muitas vezes uma suplementação do mesmo para que ocorra adequada cicatrização (Lima et al., 2006), entretanto, pode ocorrer a formação de cicatrizes patológicas, decorrentes de 
respostas anormais ao trauma como cicatriz hipertrófica e queloide (Chua et al., 2016). Quanto maior a superfície corpórea queimada, maiores as sequelas funcionais e estéticas (Rabello et al., 2014).

Geralmente o processo de cicatrização das feridas acontece de uma forma dinâmica e equilibrada, quando ocorre um desequilíbrio nesse regulamento aparecem cicatrizes hipertróficas ou queloides decorrentes do processo de cicatrização com aumento na produção de fibrinogênio e colágeno, provocando dores e restrições de movimento (Carswell, Borger 2020).

A síndrome compartimental pode ocorrer na região de tronco decorrente de queimaduras dérmicas profundas e circulares, sendo necessário realizar uma escarotomia e/ou fasciotomia (Spanholtz et al., 2009). As queimaduras que afetam à região abdominal de forma circular ocasionam aumento significativo na pressão intra-abdominal, com repercussões orgânicas significativas, fazendo-se necessário a realização da escarotomia para alívio da pressão abdominal (Kollias, Stampolidis, Castana, 2015).

O comprometimento pulmonar decorrente das cicatrizes de tronco pode ser detectado por medidas de volumes pulmonares com a mensuração da frequência respiratória (FR), ou número de incursões respiratórias por minuto (Saraiva, 1996), volume minuto (VM), ou quantidade de ar novo que entra nas vias respiratórias por minuto, sendo o produto da frequência respiratória pelo volume corrente, e o volume corrente (VC) que representa o volume de ar circulado entre uma inalação e exalação normal (Carvalho, Júnior, Franca, 2007).

A mensuração da função muscular é uma ferramenta frequentemente usada para quantificar a força muscular respiratória, realizada geralmente pela medida das pressões inspiratórias máximas (PImáx) e expiratórias (PEmáx), sendo métodos não invasivos e amplamente aceitos (Bessa, Lopes, Ruffino., 2015).

Avaliações objetivas da maleabilidade da pele a fim de detectar possíveis alterações das 
propriedades biomecânicas frente diferentes acometimentos são de grande importância (Verhaegen et al., 2010). Existem equipamentos que avaliam diferentes aspectos da pele de forma objetiva, com boa reprodutibilidade e menor variação como o cutômetro e o durômetro (Brusselaers et al., 2010; Brewin, Lister, 2014).

As complicações pulmonares após queimaduras de tronco podem ser frequentes, contudo ainda não estão bem definidas. Diante do exposto, o objetivo do estudo é avaliar a influênciadas das características biomecânicas das cicatrizes de tronco pós-queimadura na função pulmonar, muscular respiratória de indivíduos tabagistas. 


\section{HIPÓTESE}




\section{HIPÓTESE}

Postula-se a hipótese de que as cicatrizes de tronco em indivíduos tabagistas na fase crônica bem como suas sequelas, influenciem negativamente na função pulmonar. 
OBJETIVOS 


\section{OBJETIVOS}

\subsection{Objetivo geral}

Avaliar a influência da queimadura cutânea de tronco, na fase crônica, na função pulmonar, muscular respiratória em indivíduos tabagistas.

\subsection{Objetivos específicos}

- Avaliar a influência da cicatriz de tórax no paciente queimado na fase crônica, na expansibilidade torácica;

- Avaliar a maleabilidade do tecido cicatricial;

- Avaliara a firmeza do tecido cicatricial;

- Avaliar a intensidade da dor durante a expansãopulmonar;

- Correlacionar a maleabilidade e área da cicatriz com a expansibilidade torácica. 
MATERIAL E MÉTODOS 


\section{MATERIAL E MÉTODOS}

Foram convidados a participar deste estudo 40 pacientes de ambos os sexos com idade entre 18 a 75 anos, divididos em dois grupos: indivíduos não tabagistas na fase crônica, indivíduos tabagistas na fase crônica, sem distinção de raça, classe ou grupo social, atendidos na Unidade de Queimados da Unidade de Emergência - do Hospital das Clínicas da Faculdade de Medicina de Ribeirão Preto da Universidade de São Paulo (UQ/ UE /HCFMRP/USP).

Para o recrutamento, foram selecionados os pacientes em atendimento ambulatorial na unidade de queimados, que apresentaram queimaduras de segundo grau profundo e terceiro grau no tronco, com presença de cicatriz hipertrófica.

\subsection{Delineamento do estudo}

Trata-se de um estudo prospectivo e observacional.

\subsection{Análise estatística}

Para análise estatística inicialmente os dados foram descritos através de frequências absolutas epercentuais,pormeiodemedidascomomédia(M),desvio-padrão (DP), mínimo, média e máximo. A comparação dos grupos foi feita através do teste de Mann-Whitney, técnica não paramétrica que permite a comparação de dois grupos independentes sem que haja suposições quanto à distribuição dos dados. Para as comparações entre os grupos foi proposta a análise de covariância (ANCOVA), que além de comparar grupos, permite o ajuste de covariáveis (Montgomery., 2000).

Todos os modelos foram ajustados por sexo e idade. Esses modelos têm como pressuposto 
que seus resíduos tem distribuição normal com média 0 e variância $\sigma^{2}$ constante. Nas situações em que tal pressuposto não foi observado, transformações na variável dependente foram utilizadas. Todos os gráficos apresentados foram feitos com o auxílio do software R, versão 3.4.1 e as análises, através do pacote estatístico (SAS 9.2.). Em todas as análises foi considerado um nível de significância alfa $=5 \%$.

\subsection{Aspectos éticos}

O projeto foi aprovado pelo Comitê de Ética e Pesquisa da Faculdade de Medicina de Ribeirão Preto/USP, CAAE 8341386.9.0000.540. Todos os voluntários assinaram o Termo de consentimento Livre e Esclarecido (Apêndice1).

\subsection{Amostra}

Foram incluídos 40 pacientes com média de idade $37.82( \pm 10.83)$, vítimas de queimaduras de segundo grau profundo e terceiro grau na região de tronco, tabagistas e não tabagistas divididos em dois grupos de: indivíduos não tabagistas na fase crônica (20) com média de idade 41.45 ( \pm 11.09$)$ anos, indivíduos tabagistas na fase crônica (20) com média de idade 34.2 anos $( \pm 10.57)$ de ambos os sexos.

O tamanho da amostra foi calculado com base no estudo de Angrigiani et al., (2015), sendo a variável de desfecho avaliada a cirtometria na inspiração profunda em indivíduos com queimaduras de tórax, comum poder estatístico de $80 \%$ e erro alfa de 0,05 . O programa utilizado foi o State Mate 2 (GraphPad Software ${ }^{\circledR}$ v 2.0), resultando em n=18 por grupo, considerando-se $\mathrm{n}=20$ por grupo, para compensar possíveis perdas. 


\subsection{Critérios de Inclusão}

Foram incluídos no estudo os pacientes que apresentaram queimadura cutânea de segundo grau e terceiro grau profundo e enxerto na região de tronco com cicatriz hipertrófica tabagistas e não tabagistas.

\subsection{Critérios de Exclusão}

Foram excluídos do estudo os pacientes, com doenças respiratórias,cardíacas ou deformidades torácicas prévias, como doença pulmonar obstrutiva crônica, asma, bronquite, enfisema pulmonar, insuficiência cardíaca, insuficiência cardíaca congestiva, doenças de chagas, escolioses que possam interferir na avaliação e procedimentos.

\subsection{Ficha de Avaliação Respiratória no Paciente Queimado}

Foi desenvolviada uma ficha específica para avaliação respiratória do paciente vítma de queimadura na fase crônica, sendo coletado dados pessoais (idade, peso, sexo, altura, índice de massa corpórea, porcentagem de superfície corpórea queimada), dados da queimadura (agente causal, data da queimadura, área atingida ,local do acidente), dados do paciente (dor, padrão respiratório), avaliação da força muscular respiratória (Pimáx, Pemáx), avaliação da mecânica respiratória (volume corrente, volume minuto), características biomecânicas da cicatriz (maleabilidade e rigidez tecidual).

\subsection{Avaliação das propriedades Biomecânicas da Pele}

A firmeza da região afetada pela cicatriz decorrente de queimadura após epitelização foi 
analisada por um durômetro calibrado (Instruterm modelo DP-100, São Paulo, Brasil), em ambiente com temperatura e umidade controladas a $25^{\circ} \mathrm{C}$ e $50 \%$ (Klingeretal.,2013). A avaliação foi efetuada por meio de pressão perpendicular imposta pelo instrumento no tecido alvo, com repetição de três vezes, com intervalo de 10 segundos entre as mesmas (figura $1 \mathrm{~A} \mathrm{e}$ 1B).

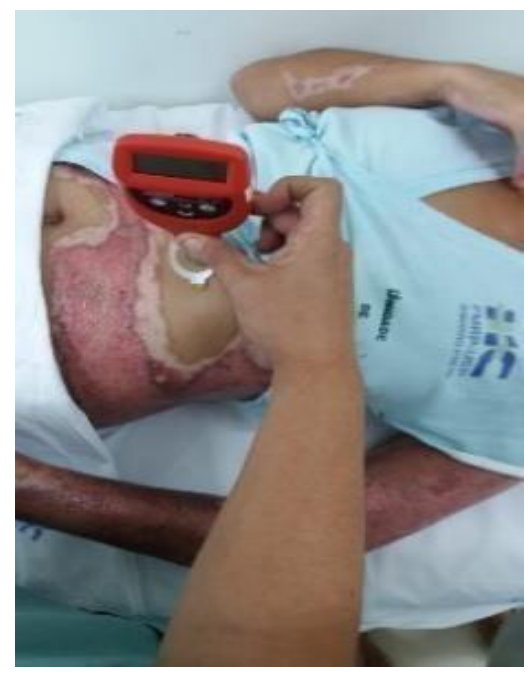

A

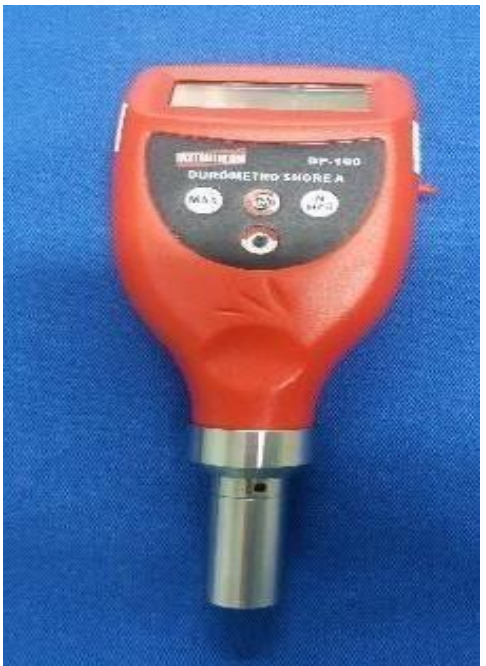

B

Figura 1 - Equipamento que avalia firmeza da pele, durômetro (figura 1A). Avaliação da firmeza da pele com durômetro (figura 1B). Fonte: Arquivo pessoal.

A avaliação das propriedades biomecânicas da pele foi efetuada com o instrumento cutômetro - Cutometer MPA 580®(Courage + Khazaka electronic GmbH, Mathias- BrüggenStraße 91, D- 50829 - Köln, Alemanha), calibrado com sonda para avaliação das características biomecânicas da pele (figura 2A e 2B)

As avaliações foram efetuadas em ambiente controlado, em posição de decúbito dorsal, no período matutino, sendo a coleta iniciada no máximo até, às 10 horas da manhã, com o intuito de se evitar interferência cronobiológica nas características da pele (Tsukahara et al., 2001). 


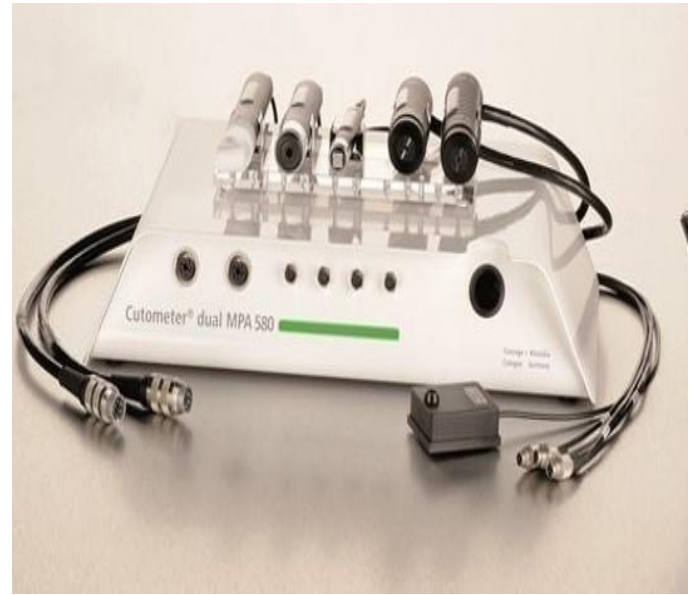

A

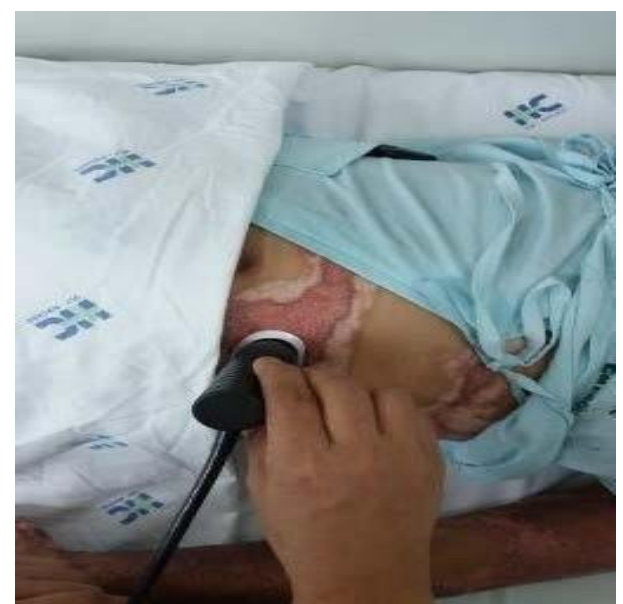

B

Figura 2 - Equipamento que avalia maleabilidade tecidual, cutômetro (figura 2A), e avaliação com o instrumento (figura 2B). Fonte: Arquivo pessoal.

\subsection{Avaliação da Função Respiratória}

\subsubsection{Avaliação da Expansibilidade Torácica}

A expansão torácica foi avaliada pela técnica de cirtometria tóraco -abdominal, na postura ortostática,que é coletada por meio de trena antropométrica 1,5 MIPSR, no tórax reepitelização sem o curativo, bem como os membros superiores ao longo do corpo. Foram avaliadas as circunferências em três pontos anatômicos: prega axilar, processo xifóide e linha umbilical, em dois diferentes momentos: inspiração máxima e expiração máxima (figuras 3A, 3B, 3C, 3D).

A diferença entre as medidas resultantes na inspiração e expiração máxima em cada nível anatômico foi considerada a mobilidade tóraco- bdominal de cada região aferida (Pedrini et al., 2013). 


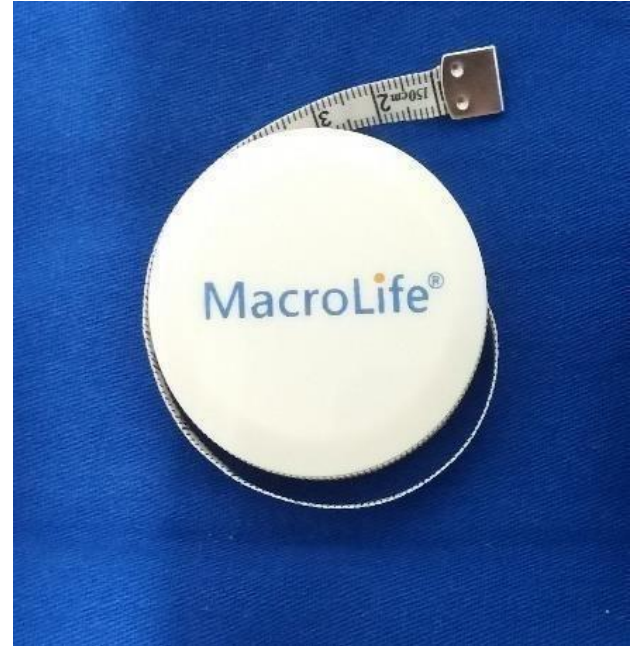

$\mathbf{A}$

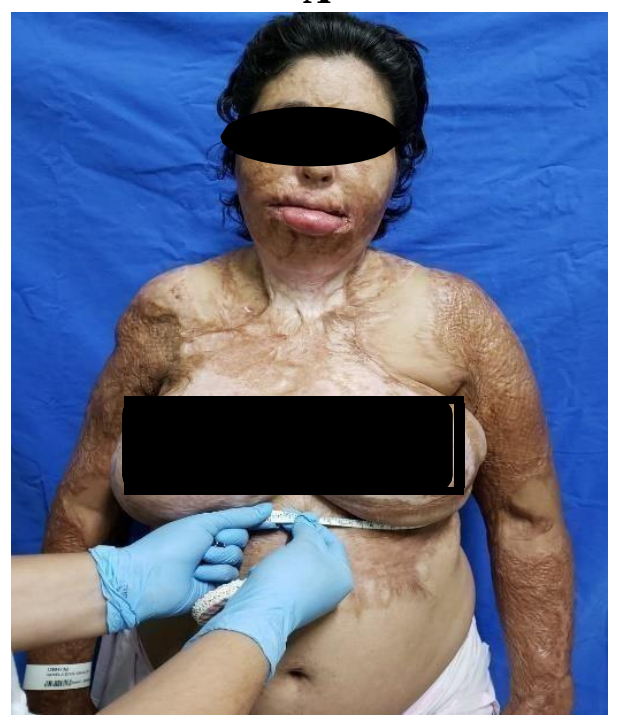

C

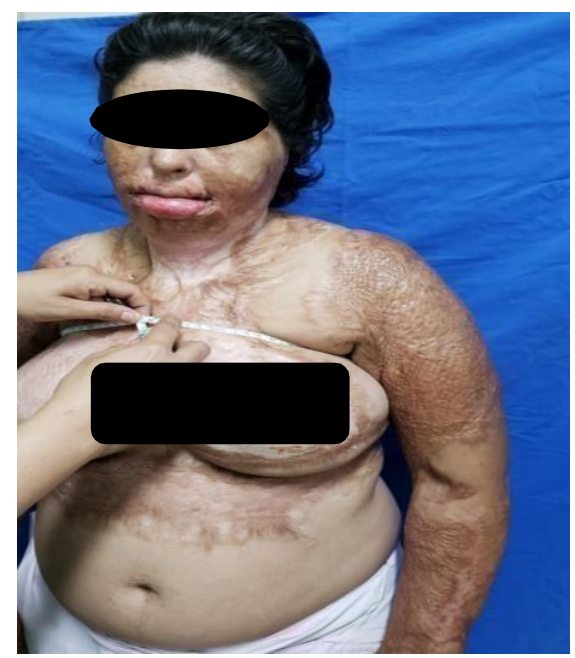

B

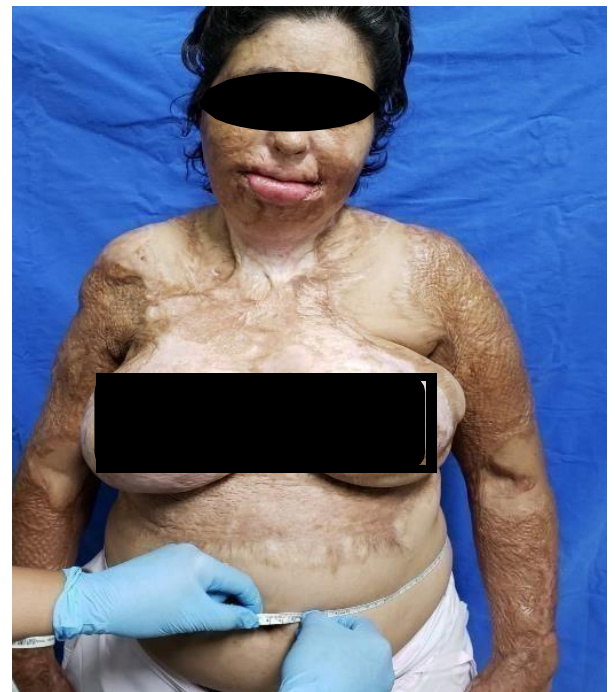

D

Figura 3 - Trena Antropométrica (figura 3A). Avaliação da expansão torácica por meio de cirtometria na prega axilar (figura 3B), processo xifoide (figura 3C) e linha umbilical (figura 3D). Fonte: Arquivo pessoal.

\subsubsection{Avaliação da Força Muscular Respiratória}

As medidas da Pressão Inspiratória máxima (PImáx) e a Pressão Expiratória máxima (PEmáx), foram efetuadas por meio de manovacuômetro digital portátil (Globalmed MVD $300^{\circledR}$, Brasil) escalonado de $1 \mathrm{em} 1 \mathrm{~cm} \mathrm{H} 2 \mathrm{O}$, com limite operacional de $\pm 300 \mathrm{~cm} \mathrm{H}_{2} \mathrm{O}$, que contém um orifício de $2 \mathrm{~mm}$ de diâmetro, servindo como válvula de alívio dos músculos bucais.

Para as medidas de pressões respiratórias máximas o voluntário permanece na posição sentada, com clipe nasal. Para avaliar a (PImáx) foi solicitado ao paciente que exalasse todo 
volume pulmonar até o volume residual (VR), em seguida foi solicitado esforço inspiratório máximo sustentado a pressão por aproximadamente dois segundos.

Para medir a (PEmáx), foi solicitado ao voluntário que insuflasse os pulmões até a capacidade pulmonar total (CPT), e então realizado uma expiração forçada sustentando a pressão máxima por aproximadamente dois segundos, sendo que cada manobra foi efetuada três vezes, com intervalo de repouso de um minuto entre as coletas, sendo considerada o maior para análise estatística (Souza, 2002).

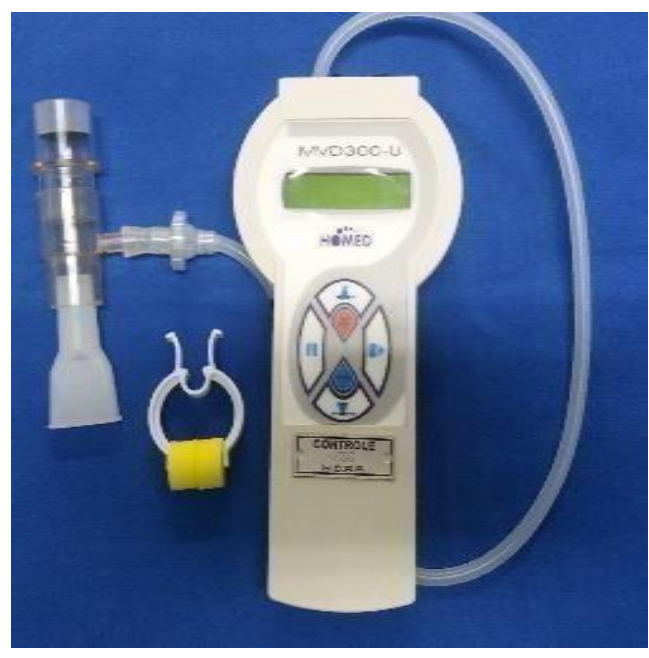

A

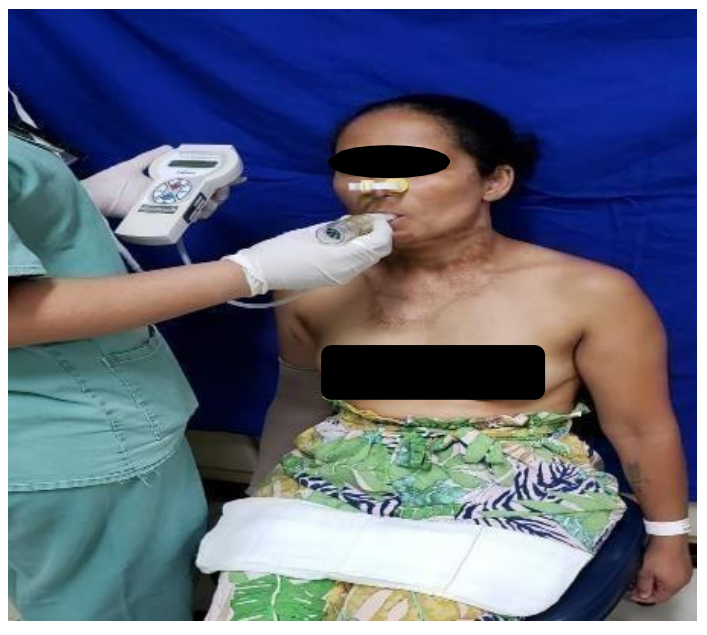

B

Figura 4 - Equipamento Manovacuômetro que avalia a pressão das forças musculares respiratórias estáticas máximas (figura 5A). Avaliação com o equipamento (figura 5B). Fonte: Arquivo pessoal.

\subsubsection{Avaliação da mecânica respiratória}

A avaliação da mecânica respiratória foi efetuada pela mensuração do volume corrente, volume minuto, FR e Capacidade Vital Lenta, por meio do ventilômetro de Wright@ analógico (Ferraris Mark 8, Wright Respirometer, Lousville, CO, EUA).

Para iniciar a coleta, o voluntário foi posicionado em uma cadeira, com a cabeça em posição neutra, membros superiores relaxados e inferiores flexionados e apoiados no chão. Foi instruído a selar e manter os lábios no bocal do equipamento, afim de não haver escape aéreo, sendo que a escala volumétricada do ventilômetro foi zerada a cada aferição. Os voluntários 
foram informados de que não poderiam falar, tossir ou sorrir enquanto o procedimento estivesse sendo realizado, para evitar interferência nas medidas. Foi solicitada uma respiração normal e tranquila por um minuto, para o registro do volume minuto e da frequência respiratória, verificada através da observação direta dos movimentos torácicos e controlada com cronômetro. Para o cálculo do volume corrente foi utilizada a equação: VC = VM/FR.

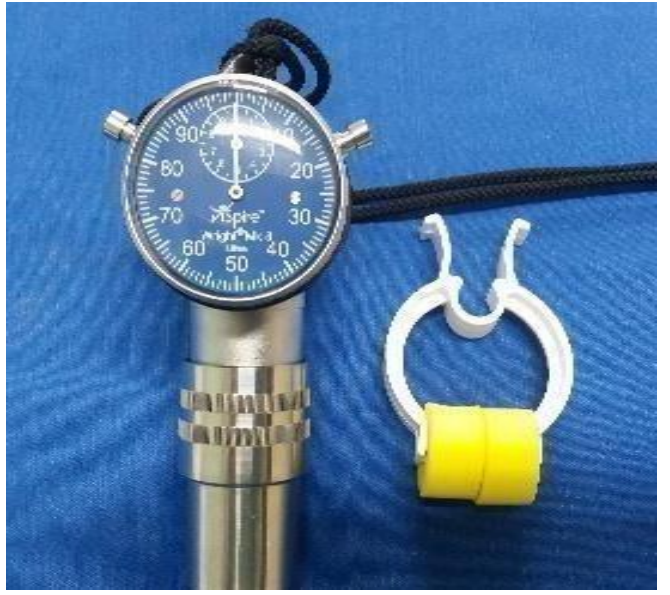

A

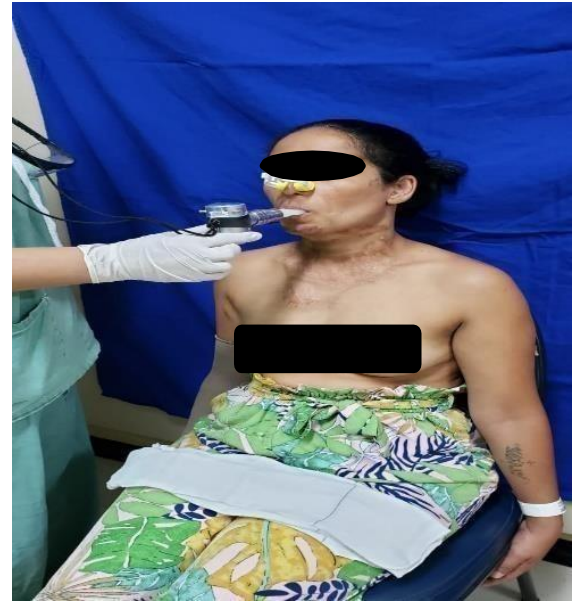

B

Figura 5 - Equipamento ventilômetro para avaliação do volume corrente, volume minuto (figura 5A). Avaliação com o equipamento (figura 5B). Fonte: Arquivo pessoal.

\subsubsection{Avaliação da dor}

A intensidade da dor nas áreas com cicatrizes hipertróficas foram avaliadas por meio de escala numérica de avaliação de dor (EVA), com pontuação variando de 0 a 10 (Anexo A), no qual o valor 0 representa "ausência dor" e 10 refere-se "a pior dor que se pode imaginar" (Ferreira-Valente etal., 2011). Foi considerada a alteração mínima detectável 2,1 pontos e diferença mínima clinicamente importante 1,3 pontos (Cleland et al.,2008). 
RESULTADOS 


\section{RESULTADOS}

\subsection{Caracterização física e social do grupo emestudo}

Foram avaliados 40 pacientes do sexo feminino e masculino com idade entre 18 e 75 anos, com cicatrizes cutâneas em tronco devido acidente por queimadura, divididos em dois grupos: indivíduo crônico tabagista e indivíduo crônico não tabagista. Foram realizados testes para avaliação da função pulmonar e força muscular respiratória máxima e utilizadosequipamentos para avaliar as características biomecânicas da pele.

A caracterização da amostra, em termos físicos (idade, peso, sexo, altura índice de massa corpórea, porcentagem de superfície corpórea queimada), encontra-se descrita, como média e desvio padrão (DP), na Tabela 1.

Tabela 1 - Características físicas dos pacientes estudados. $\mathbf{N}=\mathbf{4 0}$

\begin{tabular}{lcc}
\hline \multicolumn{1}{c}{ Variáveis } & Média (DP) GCT & Média (DP) GCNT \\
\hline Idade (anos) & $41.45(11.09)$ & $34.2(10.57)$ \\
Peso (Kg) & $70.9(13.15)$ & $70.8(14.59)$ \\
Sexo F & $12(60 \%)$ & $14(70 \%)$ \\
Sexo M & $8(40 \%)$ & $6(30 \%)$ \\
Altura (m) & $1.68(0.08)$ & $1.65(0.09)$ \\
IMC (Kg/m $\left.\mathbf{~}^{2}\right)$ & $25.21(4.05)$ & $25.76(4.72)$ \\
\% SCQ & $20.03(7.84)$ & $19.78(7.72)$ \\
\hline
\end{tabular}

Valores expressos com média e desvio padrão. IMC: índice de massa corpórea; \% SCQ: porcentagem de superfície corpórea queimada; GCNT: grupo com queimadura crônica não tabagista; GCT: grupo com queimadura crônica tabagista. 
Em relação as variáveis do local em que ocorreu o acidente da queimadura, foram divididos em: ambiente aberto, fechado e semi berto, os resultados encontram-se descritos na Tabela 2.

Tabela 2 - Descrição do local do acidente.

\begin{tabular}{lccc}
\hline \multirow{2}{*}{ Local do acidente } & \multicolumn{3}{c}{ Grupo } \\
\cline { 2 - 4 } Aberto & $\begin{array}{c}\text { Crônico não } \\
\text { tabagista }\end{array}$ & Crônico tabagista & Total \\
Fechado & $8(40 \%)$ & $11(55 \%)$ & 19 \\
Semiaberto & $4(20 \%)$ & $8(40 \%)$ & 16 \\
\hline Total & 20 & $1(5 \%)$ & 5 \\
\hline
\end{tabular}

Valores descritos como média e desvio padrão.

A média e o desvio padrão dos valores obtidos referentes ao agente causador estão representados na Tabela 3, sendo que a maioria dos acidentes ocorreu em ambiente aberto.

Tabela 3 - Valores referentes ao agente causador da queimadura.

\begin{tabular}{lccc}
\hline \multirow{2}{*}{ Agente } & \multicolumn{2}{c}{ Grupo } & \\
\cline { 2 - 3 } & Crônico não tabagista & Crônico tabagista & Total \\
\hline Acetona & $2(10 \%)$ & $1(5 \%)$ & 3 \\
Bagaço de cana & $0(0 \%)$ & $1(5 \%)$ & 1 \\
Chama direta & $0(0 \%)$ & $1(5 \%)$ & 1 \\
Choque elétrico & $0(0 \%)$ & $1(5 \%)$ & 1 \\
Escaldadura & $1(5 \%)$ & $0(0 \%)$ & 1 \\
Explosão panela pressão & $1(5 \%)$ & $0(0 \%)$ & 1 \\
Gasolina & $1(5 \%)$ & $0(0 \%)$ & 1 \\
Química & $2(10 \%)$ & $0(0 \%)$ & 2 \\
Álcool etílico (etanol) & $12(60 \%)$ & $15(75 \%)$ & 27 \\
Ácido & $1(5 \%)$ & $0(0 \%)$ & 1 \\
\hline Total & 20 & 20 & 40 \\
\hline
\end{tabular}

Valores descritos com média e desvio padrão. 
Na Tabela 4 foram descritos a média e o desvio padrão referentes aos valores do padrão respiratório dos pacientes avaliados.

Tabela 4 - Valores referentes ao padrão respiratório dos pacientes analisados.

\begin{tabular}{lccc}
\hline \multirow{2}{*}{ Padrão respiratório } & \multicolumn{2}{c}{ Grupo } & \\
\cline { 2 - 3 } & Crônico não tabagista & Crônico tabagista & Total \\
\hline Apical & $4(20 \%)$ & $8(40 \%)$ & 12 \\
Diafragmático & $1(5 \%)$ & $1(5 \%)$ & 2 \\
Misto & $15(75 \%)$ & $11(55 \%)$ & 26 \\
\hline Total & 20 & 20 & 40 \\
\hline
\end{tabular}

Valores descritos com média e desvio padrão.

Na Tabela 5 estão representados a média e o desvio padrão dos valores obtidos durante a inspiração pulmonar máxima, apontam que a dor não é um fator que afeta o movimento respiratório.

Tabela 5 - Valores referentes a análise de dor dos pacientes obtidos pela técnica da cirtometria.

\begin{tabular}{lccc}
\hline Dor & GCT & GCNT & Total \\
\hline Não & $15(75 \%)$ & $16(80 \%)$ & 31 \\
Sim & $5(25 \%)$ & $4(20 \%)$ & 9 \\
\hline Total & 20 & 20 & 40 \\
\hline
\end{tabular}

Valores descritos com média e desvio padrão, GCT: grupo crônico tabagista; GCNT: grupo crônico tabagista.

\subsection{Avaliações da influência da queimadura sobre parâmetros respiratórios}

A porcentagem média (desvio padrão) de superfície corpórea queimada foi de 19.9 $( \pm 7,78)$ no grupo total de pacientes, cicatriz hipertrófica $100 \%$, sendo no grupo crônico tabagista $60 \%$ do sexo feminino (12) e $40 \%$ do sexo masculino (12). No grupo crônico não 
tabagista $70 \%$ do sexo feminino (14) e 30\% do sexo masculino (6). A Tabela 6 apresenta os valores obtidos em relação à Pimáx nos grupos avaliados com o valor medido e o valor previsto da amostra.

Tabela 6 - Valores referentes aos parâmetros respiratórios, pressão inspiratória máxima e pressão expiratória máxima dos pacientes avaliados.

\begin{tabular}{|c|c|c|}
\hline \multirow[b]{2}{*}{ Grupo } & \multicolumn{2}{|c|}{ PImáx } \\
\hline & $\begin{array}{c}\text { Medido } \\
\text { Média (DP) }\end{array}$ & $\begin{array}{c}\text { Previsto } \\
\text { Média (DP) }\end{array}$ \\
\hline \multicolumn{3}{|c|}{$\overline{\text { GCT }}$} \\
\hline $\mathrm{F}$ & $82(13,44)$ & $59,27(3,44)$ \\
\hline M & $100,17(17,93)$ & $185,25(19,76)$ \\
\hline \multicolumn{3}{|c|}{ GCNT } \\
\hline $\mathrm{F}$ & $70,83(6,22)$ & $54,09(5,75)$ \\
\hline M & $90,5(30,6)$ & $185,41(9,86)$ \\
\hline
\end{tabular}

Valores expressos com média e desvio padrão. GCT: grupo crônico tabagista; GCNT: grupo crônico não tabagista; PI máx: pressão inspiratória máxima medida e prevista.

Na Tabela 7 foi descrito a estimativa, o valor de p, o índice de confiabilidade (95\%) e o effect size dos valores referentes à PImáx. Os resultados apontam que não houve diferença estatística significativa entre os grupos.

Tabela 7 - Valores referentes a variável dependente PImáx e valores das variáveis independentes.

\begin{tabular}{lccccc}
\hline \multicolumn{7}{c}{ ANCOVA } & & & & \\
\hline Variáveis independentes & Estimativa* & Valor p & IC95\%* & Effect size \\
\hline Sexo (Feminino vs Masculino) & $-0,213$ & $<0,01$ & $-0,356$ & $-0,070$ & 0,265 \\
Idade & 0,004 & 0,23 & $-0,002$ & 0,010 & 0,056 \\
IMC - índice de massa corpórea & $-0,005$ & 0,54 & $-0,020$ & 0,011 & 0,015 \\
Grupo (crônico não tabagista vs & 0,144 & 0,05 & $-0,002$ & 0,290 & 0,137 \\
crônico tabagista) & 0,010 & 0,68 & $-0,040$ & 0,061 & 0,007 \\
Firmeza da pele média controle & 0,001 & 0,96 & $-0,019$ & 0,020 & 0,000 \\
Firmeza da pele média 2 $2^{\mathbf{o}}$ profundo & 0,003 & 0,67 & $-0,012$ & 0,018 & 0,007 \\
Firmeza da pele média enxerto & $-0,068$ & 0,85 & $-0,807$ & 0,671 & 0,001 \\
Maleabilidade da pele controle & 0,450 & 0,26 & $-0,361$ & 1,262 & 0,048 \\
Maleabilidade da pele 2 ${ }^{\circ}$ profundo & $-0,130$ & 0,55 & $-0,569$ & 0,308 & 0,014 \\
Maleabilidade da pele enxerto & & & & &
\end{tabular}

* transformação raiz quadrada. 
A Tabela 8 apresenta os valores obtidos em relação à Pemáx nos grupos avaliados como valor medido e o valor previsto da amostra.

Tabela 8 - Valores referentes aos parâmetros respiratórios, pressão expiratória máxima dos pacientes avaliados.

\begin{tabular}{|c|c|c|}
\hline \multirow[b]{2}{*}{ Grupo } & \multicolumn{2}{|c|}{ PEmáx } \\
\hline & Medido & Previsto \\
\hline & Média (DP) & Média (DP) \\
\hline 0 & $8420(1234)$ & $07 ?(5,00)$ \\
\hline M & $119,5(28,4)$ & $135,43(20,08)$ \\
\hline & & \\
\hline $\mathrm{F}$ & $88,42(9,29)$ & $89,54(8,51)$ \\
\hline M & $99,86(28,18)$ & $135,59(10,02)$ \\
\hline
\end{tabular}

Valores expressos com média e desvio padrão. GCT: grupo crônico tabagista; GCNT: grupo crônico não tabagista; PEmáx: pressão expiratória máxima medida e prevista.

Na Tabela 9 foi descrito a estimativa, o valor de p, o índice de confiabilidade (95\%) e o effect size dos valores referentes à PEmáx. Os resultados apontam que não houve diferença significativa entre os grupos.

Tabela 9 - Valores referentes a variável dependente PEmáx e valores das variáveis independentes.

\begin{tabular}{|c|c|c|c|c|c|}
\hline \multicolumn{6}{|c|}{ ANCOVA } \\
\hline Variáveis independentes & Estimativa & Valor p & ICS & & Effect size \\
\hline Sexo (Feminino vs Masculino) & $-18,04$ & $<0,01$ & $-31,17$ & $-4,90$ & 0,242 \\
\hline Idade & 0,04 & 0,89 & $-0,52$ & 0,60 & 0,001 \\
\hline IMC - índice de massa corpórea & 2,85 & $<0,01$ & 1,45 & 4,25 & 0,412 \\
\hline $\begin{array}{l}\text { Grupo (crônico não tabagista vs } \\
\text { crônico tabagista) }\end{array}$ & $-0,50$ & 0,94 & $-13,36$ & 12,37 & 0,000 \\
\hline Firmeza da pele média controle & 4,50 & 0,049 & 0,03 & 8,98 & 0,147 \\
\hline Firmeza da pele média $2^{\circ}$ profundo & $-1,20$ & 0,17 & $-2,95$ & 0,54 & 0,075 \\
\hline Firmeza da pele média enxerto & 0,26 & 0,69 & $-1,07$ & 1,60 & 0,007 \\
\hline Maleabilidade da pele controle & $-61,00$ & 0,06 & $-125,52$ & 3,53 & 0,132 \\
\hline Maleabilidade da pele $2^{\circ}$ profundo & $-19,99$ & 0,57 & $-92,14$ & 52,17 & 0,013 \\
\hline Maleabilidade da pele enxerto & $-20,64$ & 0,29 & $-59,58$ & 18,31 & 0,046 \\
\hline
\end{tabular}

*transformação raiz quadrada. 
Na Tabela 10 são apresentados os valores obtidos em relação à cirtometria axilar inicial em relação aos grupos avaliados e as variáveis independentes.

Tabela 10 - Valores referentes a variável dependente cirtometria axilar inicial e valores das variáveis independentes.

\begin{tabular}{lccccc}
\hline \multicolumn{7}{c}{ ANCOVA } & & & \\
\hline Variáveis independentes & Estimativa* $^{*}$ & Valor $\mathbf{p}$ & \multicolumn{2}{c}{ IC95\% * } & Effect size \\
\hline Sexo (Feminino vs masculino) & 0,020 & 0,96 & $-0,848$ & 0,888 & 0,000 \\
Idade & 0,016 & 0,39 & $-0,022$ & 0,054 & 0,033 \\
IMC - índice de massa corpórea & 0,051 & 0,27 & $-0,043$ & 0,146 & 0,042 \\
Grupo (crônico não tabagista vs & $-0,844$ & 0,06 & $-1,729$ & 0,040 & 0,125 \\
crônico tabagista) & $-0,036$ & 0,81 & $-0,343$ & 0,271 & 0,002 \\
Firmeza da pele média controle & 0,014 & 0,82 & $-0,107$ & 0,134 & 0,002 \\
Firmeza da pele média 2 ${ }^{\circ}$ profundo & 0,049 & 0,28 & $-0,042$ & 0,141 & 0,043 \\
Firmeza da pele média enxerto & $-0,323$ & 0,88 & $-4,805$ & 4,158 & 0,001 \\
Maleabilidade da pele controle & 3,232 & 0,19 & $-1,691$ & 8,156 & 0,064 \\
Maleabilidade da pele 2 ${ }^{\circ}$ profunda & $-0,564$ & 0,67 & $-3,223$ & 2,095 & 0,007 \\
Maleabilidade da pele enxerto & & & & & \\
\hline
\end{tabular}

* transformação raiz quadrada.

A Tabela 11 apresenta os valores referentes a avaliação da cirtometria axilar inspiratória em relação aos grupos e as variáveis independentes.

Tabela 11 - Valores referentes a variável dependente cirtometria axilar inspiratória e valores das variáveis independentes.

\begin{tabular}{|c|c|c|c|c|c|}
\hline \multicolumn{6}{|c|}{ ANCOVA } \\
\hline \multirow{2}{*}{$\begin{array}{l}\text { Variáveis independentes } \\
\text { Sexo (Feminino vs Masculino) }\end{array}$} & \multirow{2}{*}{$\frac{\text { Estimativa* }}{0,020}$} & \multirow{2}{*}{$\frac{\text { Valor p }}{0,96}$} & \multicolumn{2}{|c|}{ IC95\%* } & \multirow{2}{*}{$\frac{\text { Effect size }}{0,000}$} \\
\hline & & & $-0,848$ & 0,888 & \\
\hline Idade & 0,016 & 0,39 & $-0,022$ & 0,054 & 0,029 \\
\hline IMC - índice de massa corpórea & 0,051 & 0,27 & $-0,043$ & 0,146 & 0,046 \\
\hline $\begin{array}{l}\text { Grupo (crônico não tabagista vs } \\
\text { crônico tabagista) }\end{array}$ & $-0,844$ & 0,06 & $-1,729$ & 0,040 & 0,129 \\
\hline Firmeza da pele média controle & $-0,036$ & 0,81 & $-0,343$ & 0,271 & 0,002 \\
\hline Firmeza da pele média $2^{\circ}$ profundo & 0,014 & 0,82 & $-0,107$ & 0,134 & 0,002 \\
\hline Firmeza da pele média enxerto & 0,049 & 0,28 & $-0,042$ & 0,141 & 0,045 \\
\hline Maleabilidade da pele controle & $-0,323$ & 0,88 & $-4,805$ & 4,158 & 0,001 \\
\hline Maleabilidade da pele $2^{\circ} \mathrm{P}$ & 3,232 & 0,19 & $-1,691$ & 8,156 & 0,065 \\
\hline Maleabilidade da pele enxerto & $-0,564$ & 0,67 & $-3,223$ & 2,095 & 0,007 \\
\hline
\end{tabular}

* transformação raiz quadrada. 
Na Tabela 12 encontram-se os valores obtidos em relação a cirtometria axilar expiratória em relação aos grupos e as variáveis independentes. Os resultados apontam que não houve diferença estatística significativa entre os grupos.

Tabela 12 - Valores referentes a variável dependente cirtometria axilar expiratória e valores das variáveis independentes.

\begin{tabular}{lccccc}
\hline \multicolumn{7}{c}{ ANCOVA } \\
\hline Variáveis independentes & Estimativa* $^{*}$ & Valor p & \multicolumn{2}{c}{ IC95\% } & Effect size \\
\hline Sexo (Feminino vs Masculino) & $-1,76$ & 0,80 & $-16,06$ & 12,54 & 0,054 \\
Idade & 0,26 & 0,41 & $-0,37$ & 0,88 & 0,046 \\
IMC - índice de massa corpórea & 0,82 & 0,29 & $-0,74$ & 2,37 & 0,134 \\
Grupo (crônico não tabagista vs & $-15,90$ & 0,03 & $-30,48$ & $-1,32$ & 0,069 \\
crônico tabagista) & $-1,48$ & 0,55 & $-6,54$ & 3,59 & 0,013 \\
Firmeza da pele média controle & 0,51 & 0,60 & $-1,48$ & 2,50 & 0,001 \\
Firmeza da pele média 2 ${ }^{\circ}$ profundo & 0,72 & 0,34 & $-0,79$ & 2,22 & 0,095 \\
Firmeza da pele média enxerto & $-12,30$ & 0,73 & $-86,15$ & 61,55 & 0,001 \\
Maleabilidade da pele controle & 39,30 & 0,33 & $-41,83$ & 120,44 & 0,064 \\
Maleabilidade da pele 2 ${ }^{\circ}$ profundo & $-0,55$ & 0,98 & $-44,36$ & 43,27 & 0,021 \\
Maleabilidade da pele enxerto & & & & & \\
\hline
\end{tabular}

* transformação raiz quadrada.

Na Tabela 13 são apresentados os valores obtidos em relação à cirtometria xifoide inicial em relação aos grupos avaliados e as variáveis independentes.

Tabela 13 - Valores referentes a variável dependente cirtometria xifoide inicial e valores das variáveis independentes.

\begin{tabular}{|c|c|c|c|c|c|}
\hline \multicolumn{6}{|c|}{ ANCOVA } \\
\hline Variáveis independentes & Estimativa* & Valor p & & & Effect size \\
\hline Sexo (Feminino vs masculino) & $-2,27$ & 0,75 & $-16,84$ & 12,30 & 0,033 \\
\hline Idade & 0,25 & 0,43 & $-0,39$ & 0,89 & 0,007 \\
\hline IMC - índice de massa corpórea & 0,75 & 0,34 & $-0,84$ & 2,33 & 0,085 \\
\hline $\begin{array}{l}\text { Grupo (crônico não tabagista vs crônico } \\
\text { tabagista) }\end{array}$ & $-16,04$ & 0,04 & $-30,89$ & $-1,19$ & 0,118 \\
\hline Firmeza da pele média controle & $-1,28$ & 0,61 & $-6,45$ & 3,88 & 0,047 \\
\hline Firmeza da pele média $2^{\circ}$ profundo & 0,42 & 0,67 & $-1,60$ & 2,45 & 0,043 \\
\hline Firmeza da pele média enxerto & 0,72 & 0,34 & $-0,81$ & 2,26 & 0,002 \\
\hline Maleabilidade da pele controle & $-13,06$ & 0,72 & $-88,30$ & 62,18 & 0,001 \\
\hline Maleabilidade da pele $2^{\circ}$ profundo & 41,42 & 0,31 & $-41,24$ & 124,09 & 0,014 \\
\hline Maleabilidade da pele enxerto & $-0,18$ & 0,99 & $-44,82$ & 44,46 & 0,001 \\
\hline
\end{tabular}

* transformação raiz quadrada. 
A Tabela 14 apresenta os valores referentes a avaliação da cirtometria xifoide inspiratória em relação aos grupos e as variáveis independentes.

Tabela 14 - Valores referentes a variável dependente cirtometria xifoide inspiratória e valores das variáveis independentes.

\begin{tabular}{lccccc}
\hline \multicolumn{9}{c}{ ANCOVA } & & & \\
\hline Variáveis independentes & Estimativa* $^{*}$ & Valor $\mathbf{p}$ & IC95\% & & Effect size \\
\hline Sexo (Feminino vs masculino) & $-1,76$ & 0,58 & $-16,84$ & 12,30 & 0,004 \\
Idade & 0,26 & 0,44 & $-0,39$ & 0,89 & 0,024 \\
IMC - índice de massa corpórea & 0,82 & 0,31 & $-0,84$ & 2,33 & 0,035 \\
Grupo (crônico não tabagista vs & $-15,90$ & 0,05 & $-30,89$ & $-1,19$ & 0,159 \\
crônico tabagista) & $-1,48$ & 0,62 & $-6,45$ & 3,88 & 0,010 \\
Firmeza da pele média controle & 0,51 & 0,54 & $-1,60$ & 2,45 & 0,007 \\
Firmeza da pele média 2 ${ }^{\circ}$ profundo & 0,72 & 0,51 & $-0,81$ & 2,26 & 0,035 \\
Firmeza da pele média enxerto & $-12,30$ & 0,80 & $-88,30$ & 62,18 & 0,005 \\
Maleabilidade da pele controle & 39,30 & 0,63 & $-41,24$ & 124,09 & 0,039 \\
Maleabilidade da pele 2 ${ }^{\mathbf{o}}$ profundo & $-0,55$ & 0,76 & $-44,82$ & 44,46 & 0,000 \\
\hline Maleabilidade da pele enxerto & & & & & \\
\hline
\end{tabular}

* transformação quadrática.

Na Tabela 15 encontram-se os valores obtidos em relação a cirtometria xifoide expiratória em relação aos grupos e as variáveis independentes. Os resultados apontam que não houve diferença estatística significativa entre os grupos.

Tabela 15 - Valores referentes a variável dependente cirtometria xifóide expiratória e valores das variáveis independentes.

\begin{tabular}{lccccc}
\hline & ANCOVA & \multicolumn{3}{c}{} \\
\hline Variáveis independentes & Estimativa* $^{*}$ & Valor p & IC95\% & Effect size \\
\hline Sexo (Feminino vs masculino) & $-6,37$ & 0,36 & $-20,49$ & 7,75 & 0,012 \\
Idade & 0,12 & 0,68 & $-0,50$ & 0,74 & 0,023 \\
IMC - índice de massa corpórea & 1,14 & 0,14 & $-0,40$ & 2,68 & 0,039 \\
Grupo (crônico não tabagista vs & $-12,97$ & 0,08 & $-27,57$ & 1,63 & 0,143 \\
crônico tabagista) & $-2,70$ & 0,28 & $-7,72$ & 2,31 & 0,010 \\
Firmeza da pele média controle & 1,01 & 0,30 & $-0,96$ & 2,99 & 0,015 \\
Firmeza da pele média 2 ${ }^{\circ}$ profundo & 0,15 & 0,83 & $-1,34$ & 1,65 & 0,017 \\
Firmeza da pele média enxerto & $-6,27$ & 0,86 & $-79,21$ & 66,68 & 0,003 \\
Maleabilidade da pele controle & 23,61 & 0,56 & $-58,52$ & 105,75 & 0,009 \\
Maleabilidade da pele 2 ${ }^{\circ}$ profundo & $-3,21$ & 0,88 & $-46,45$ & 40,04 & 0,004 \\
Maleabilidade da pele enxerto & & & & & \\
\hline
\end{tabular}

* transformação raiz quadrada. 
A Tabela 16 apresenta os valores obtidos em relação à cirtometria umbilical inicial em relação aos grupos avaliados e as variáveis independentes.

Tabela 16 - Valores referentes a variável dependente cirtometria umbilical inicial e valores das variáveis independentes.

\begin{tabular}{lccccc}
\hline \multicolumn{7}{c}{ ANCOVA } & \multicolumn{2}{c}{} \\
\hline Variáveis independentes & Estimativa* $^{*}$ & Valor p & \multicolumn{2}{c}{ IC95\% } & Effect size \\
\hline Sexo (Feminino vs masculino) & $-6,78$ & 0,30 & $-20,09$ & 6,53 & 0,033 \\
Idade & 0,11 & 0,71 & $-0,48$ & 0,69 & 0,007 \\
Grupo (crônico não tabagista vs & $-13,52$ & 0,05 & $-27,09$ & 0,04 & 0,118 \\
crônico tabagista) & $-2,81$ & 0,23 & $-7,53$ & 1,90 & 0,047 \\
Firmeza da pele média controle & 1,07 & 0,25 & $-0,78$ & 2,92 & 0,043 \\
Firmeza da pele média 2 $2^{\circ}$ profundo & 0,06 & 0,93 & $-1,34$ & 1,46 & 0,002 \\
Firmeza da pele média enxerto & $-6,14$ & 0,86 & $-74,86$ & 62,57 & 0,001 \\
Maleabilidade da pele controle & 27,76 & 0,46 & $-47,73$ & 103,26 & 0,014 \\
Maleabilidade da pele 2 ${ }^{\circ}$ profundo & $-2,84$ & 0,89 & $-43,62$ & 37,93 & 0,001 \\
Maleabilidade da pele enxerto & & & & & \\
\hline
\end{tabular}

* transformação raiz quadrada.

Os valores referentes a avaliação da cirtometria umbilical inspiratória em relação aos grupos e as variáveis independentes estão descritos na Tabela 17.

Tabela 17 - Valores referentes a variável dependente cirtometria umbilical inspiratória e valores das variáveis independentes.

\begin{tabular}{lccccc}
\hline \multicolumn{7}{c}{ ANCOVA } & \multicolumn{3}{c}{} \\
\hline Variáveis independentes & Estimativa* $^{*}$ & Valor p & \multicolumn{2}{c}{ IC95\% } & Effect size \\
\hline Sexo (Feminino vs masculino) & $-6,78$ & 0,30 & $-20,09$ & 6,53 & 0,041 \\
Idade & 0,11 & 0,71 & $-0,48$ & 0,69 & 0,006 \\
IMC - índice de massa corpórea & 1,16 & 0,11 & $-0,29$ & 2,61 & 0,094 \\
Grupo (crônico não tabagista vs & $-13,52$ & 0,05 & $-27,09$ & 0,04 & 0,139 \\
crônico tabagista) & $-2,81$ & 0,23 & $-7,53$ & 1,90 & 0,055 \\
Firmeza da pele média controle & 1,07 & 0,25 & $-0,78$ & 2,92 & 0,051 \\
Firmeza da pele média 2 ${ }^{\mathbf{o}}$ profundo & 0,06 & 0,93 & $-1,34$ & 1,46 & 0,000 \\
Firmeza da pele média enxerto & $-6,14$ & 0,86 & $-74,86$ & 62,57 & 0,001 \\
Maleabilidade da pele controle & 27,76 & 0,46 & $-47,73$ & 103,26 & 0,022 \\
Maleabilidade da pele 2 ${ }^{\mathbf{o}}$ profundo & $-2,84$ & 0,89 & $-43,62$ & 37,93 & 0,001 \\
Maleabilidade da pele enxerto & & & & &
\end{tabular}

* transformação raiz quadrada. 
Na Tabela 18 encontram-se os valores obtidos em relação a cirtometria umbilical expiratória em relação aos grupos e as variáveis independentes. Os resultados apontam que não houve diferença significativa entre osgrupos.

Tabela 18 - Valores referentes a variável dependente cirtometria umbilical expiratória e valores das variáveis independentes.

\begin{tabular}{lccccc}
\hline \multicolumn{7}{c}{ ANCOVA } & & \\
\hline Variáveis independentes & Estimativa* & Valor $\mathbf{p}$ & \multicolumn{2}{c}{ IC95\% } & Effect size \\
\hline Sexo (Feminino vs masculino) & $-7,03$ & 0,30 & $-20,69$ & 6,63 & 0,041 \\
Idade & 0,13 & 0,65 & $-0,46$ & 0,73 & 0,008 \\
IMC - índice de massa corpórea & 1,03 & 0,17 & $-0,46$ & 2,52 & 0,073 \\
Grupo (crônico não tabagista vs & $-12,44$ & 0,08 & $-26,36$ & 1,48 & 0,115 \\
crônico tabagista) & $-3,18$ & 0,19 & $-8,01$ & 1,66 & 0,066 \\
Firmeza da pele média controle & 1,18 & 0,21 & $-0,72$ & 3,08 & 0,059 \\
Firmeza da pele média 2 $2^{\circ}$ profundo & $-0,01$ & 0,98 & $-1,45$ & 1,42 & 0,000 \\
Firmeza da pele média enxerto & 0,04 & 1,00 & $-70,49$ & 70,57 & 0,000 \\
Maleabilidade da pele controle & 24,77 & 0,52 & $-52,71$ & 102,26 & 0,016 \\
Maleabilidade da pele 2 ${ }^{\circ}$ profundo & $-3,95$ & 0,85 & $-45,80$ & 37,90 & 0,001 \\
Maleabilidade da pele enxerto & & & & & \\
\hline
\end{tabular}

* transformação raiz quadrada, Effect size ( $\eta^{2}$ partial).

Na Tabela 19 foram descritas a estimativa, o valor de p, o índice de confiabilidade (95\%) e o effect size dos valores referentes ao volume corrente e as variáveis independentes.

Tabela 19 - Valores referentes a variável dependente volume minuto e valores das variáveis independentes.

\begin{tabular}{lccccc}
\hline \multicolumn{7}{c}{ ANCOVA } & & \\
\hline Variáveis independentes & Estimativa* $^{*}$ & Valor p & IC95\%* & Effect size \\
\hline Sexo (Feminino vs masculino) & 0,077 & 0,55 & $-0,183$ & 0,337 & 0,014 \\
Idade & 0,004 & 0,50 & $-0,008$ & 0,015 & 0,018 \\
IMC - índice de massa corpórea & $-0,009$ & 0,51 & $-0,038$ & 0,019 & 0,017 \\
Grupo (crônico não tabagista vs & 0,065 & 0,62 & $-0,200$ & 0,331 & 0,010 \\
crônico tabagista) & 0,031 & 0,50 & $-0,061$ & 0,123 & 0,018 \\
Firmeza da pele média controle & $-0,010$ & 0,56 & $-0,047$ & 0,026 & 0,013 \\
Firmeza da pele média 2 $2^{\mathbf{o}}$ profundo & 0,007 & 0,60 & $-0,020$ & 0,034 & 0,011 \\
Firmeza da pele média enxerto & 0,412 & 0,53 & $-0,931$ & 1,755 & 0,015 \\
Maleabilidade da pele controle & 0,548 & 0,45 & $-0,927$ & 2,024 & 0,022 \\
Maleabilidade da pele 2 ${ }^{\circ}$ profundo & 0,881 & $\mathbf{0 , 0 3}$ & 0,084 & 1,678 & 0,166 \\
Maleabilidade da pele enxerto & & & & & \\
\hline
\end{tabular}

* transformação logarítmica, Effect size ( $\eta^{2}$ partial). 
Na Tabela 20 foram descritas a estimativa, o valor de p, o índice de confiabilidade (95\%) e o effect size dos valores referentes ao volume minuto e as variáveis independentes. Os resultados apontam que não houve diferença significativa entre os grupos.

Tabela 20 - Valores referentes a variável dependente do volume corrente e valores de variáveis dependentes.

\begin{tabular}{|c|c|c|c|c|c|}
\hline \multicolumn{6}{|c|}{ ANCOVA } \\
\hline Variáveis independentes & Estimativa* $^{*}$ & Valor p & IC95 & $5 \% *$ & Effect size \\
\hline Sexo (Feminino vs masculino) & 167,49 & 0,14 & $-59,85$ & 394,83 & 0,081 \\
\hline Idade & 8,28 & 0,10 & $-1,68$ & 18,24 & 0,101 \\
\hline IMC - índice de massa corpórea & $-4,14$ & 0,73 & $-28,88$ & 20,60 & 0,005 \\
\hline $\begin{array}{l}\text { Grupo (crônico não tabagista vs } \\
\text { crônico tabagista) }\end{array}$ & $-87,17$ & 0,45 & $-318,91$ & 144,57 & 0,023 \\
\hline Firmeza da pele média controle & 6,12 & 0,88 & $-74,40$ & 86,63 & 0,001 \\
\hline Firmeza da pele média $2^{\circ}$ profundo & $-10,67$ & 0,49 & $-42,30$ & 20,96 & 0,018 \\
\hline Firmeza da pele média enxerto & 18,65 & 0,12 & $-5,28$ & 42,58 & 0,090 \\
\hline Maleabilidade da pele controle & $-530,70$ & 0,36 & $-1704,59$ & 643,19 & 0,032 \\
\hline Maleabilidade da pele $2^{\circ}$ profundo & $-492,35$ & 0,44 & $-1782,02$ & 797,33 & 0,023 \\
\hline Maleabilidade da pele enxerto & 397,67 & 0,25 & $-298,85$ & 1094,19 & 0,050 \\
\hline
\end{tabular}

* transformação raiz quadrada, Effect size ( $\eta^{2}$ partial).

\subsection{Resultados referentes às avaliações da influência da queimadura sobre a elasticidade e rigidez dos tecidos cicatrizados}

A Tabela 21 fornece os valores referentes a respeito da maleabilidade e da rigidez das cicatrizes avaliadas nos grupos tabagista e não tabagista. Não foram observadas diferenças significativas entre os grupos analisados.

Tabela 21 - Valores referentes à avaliação dos parâmetros de Maleabilidade e Firmeza de tecidos cicatrizados nas regiões controle, $2^{\circ}$ profundo, enxertada, da média controle, média $2^{\circ}$ profundo e média enxertada.

\begin{tabular}{|c|c|c|c|c|c|c|}
\hline Varíaveis & $\begin{array}{c}\text { Cutometer } \\
(\mathbf{m m}) \\
\text { Controle }\end{array}$ & $\begin{array}{c}\text { Cutometer } \\
(\mathbf{m m}) \\
\mathbf{2}^{\mathbf{o}} \text { prof. }\end{array}$ & $\begin{array}{c}\text { Cutometer } \\
(\mathbf{m m}) \\
\text { Enxerto }\end{array}$ & $\begin{array}{l}\text { Durometer } \\
\text { Controle }\end{array}$ & $\begin{array}{l}\text { Durometer } \\
\mathbf{2}^{\circ} \text { prof. }\end{array}$ & $\begin{array}{c}\text { Durometer } \\
\text { enxerto }\end{array}$ \\
\hline GCT & $0,21(0,06)$ & $0,14(0,08)$ & $0,18(0,22)$ & $3,43(2,2)$ & $5,39(4,2)$ & $6,65(3,85)$ \\
\hline GCNT & $0,2(0,1)$ & $0,15(0,08)$ & $0,08(0,05)$ & $3,26(1,5)$ & $6,55(6,09)$ & $10,01(7,62)$ \\
\hline
\end{tabular}

Avaliações realizadas com cutometer e durometer. Valores expressos com média e desvio padrão. GCT: grupo com queimadura crônica tabagista; GCNT: grupo com queimadura crônica tabagista. 
Na Tabela 22 estão representados a média, a mediana e o valor de p entre os grupos estudados. Não foram observadas diferenças significativas entre os grupos analisados.

Tabela 22 - Comparação da firmeza e maleabilidade da pele entre os grupos.

\begin{tabular}{|c|c|c|c|c|c|c|c|}
\hline \multirow{2}{*}{ Variável } & \multicolumn{3}{|c|}{ Crônico não tabagista } & \multicolumn{4}{|c|}{ Crônico tabagista } \\
\hline & $\mathbf{N}$ & Média (DP) & Mediana & $\mathbf{N}$ & Média (DP) & Mediana & Valor p \\
\hline $\begin{array}{l}\text { Firmeza da pele } \\
\text { média controle }\end{array}$ & 19 & $3,26(1,5)$ & $2,96(2,36 ; 3,63)$ & 20 & $3,43(2,2)$ & $2,77(2,1 ; 10,8)$ & 0,40 \\
\hline $\begin{array}{l}\text { Firmeza da pele } \\
\text { média } 2^{\circ} \text { profundo }\end{array}$ & 19 & $6,55(6,09)$ & $4,43(2,56 ; 24,06)$ & 20 & $5,39(4,2)$ & $4,65(2,53 ; 22)$ & 0,99 \\
\hline $\begin{array}{l}\text { Firmeza da pele } \\
\text { média enxerto }\end{array}$ & 19 & $10,01(7,62)$ & $7,36(3,76 ; 27,9)$ & 20 & $6,65(3,85)$ & $5,2(2,53 ; 16,4)$ & 0,07 \\
\hline $\begin{array}{l}\text { Maleabilidade da } \\
\text { pele controle }\end{array}$ & 18 & $0,2(0,1)$ & $0,18(0,06 ; 0,44)$ & 20 & $0,21(0,06)$ & $0,22(0,08 ; 0,52)$ & 0,18 \\
\hline $\begin{array}{l}\text { Maleabilidade da } \\
\text { pele } 2^{\circ} \text { profundo }\end{array}$ & 18 & $0,15(0,08)$ & $0,13(0 ; 0,28)$ & 20 & $0,14(0,08)$ & $0,12(0,01 ; 0,38)$ & 0,55 \\
\hline $\begin{array}{l}\text { Maleabilidade da } \\
\text { pele enxerto }\end{array}$ & 18 & $0,08(0,05)$ & $0,08(0 ; 0,17)$ & 20 & $0,18(0,22)$ & $0,1(0,02 ; 0,82)$ & 0,26 \\
\hline
\end{tabular}


DISCUSSÃO 


\section{DISCUSSÃO}

As cicatrizes de queimadura são geralmente retiradas e cobertas com enxertos de pele, sendo que posteriormente em lesões que afetam o tronco, o tratamento pode desencadear desconforto, capacidade pulmonar total reduzida além da restrição da expansão torácica e mobilidade articular.O presente estudo avaliou a influência da queimadura cutânea de tronco na fase crônica na função pulmonar,muscular respiratória em indivíduos tabagistas,bem como as características biomecânicas da cicatriz hipertrófica.

Os resultados relacionados a alteração aos parâmetros respiratórios e biomecânicos da pele avaliados (pressão inspiratória e expiratória máxima, cirtometria, maleabilidade e firmeza da pele) não apresentaram diferença significativa entre os grupos de indivíduos tabagistas e não tabagistas. A queimadura promove alteração das propriedades biomecânicas da pele diretamente relacionada a profundidade da lesão (Held et al., 2015), entretanto as características das variáveis de desfecho foram semelhantes entre os grupos.

A enxertia de pele é um procedimento operatório fundamental na cirurgia plástica reconstrutiva em traumas ou feridas, retiradas de tumores, infecções e queimaduras (Young, Fowler, 1998).

A associação entre a cicatrização de feridas e o tabagismo tem sido investigada (Aköz, Akan, Yildirim, 2002). A cicatrização de feridas é um processo fisiopatológico complexo, e lesões crônicas não respondem bem a um tratamento isolado, sendo reconhecida como benéfica para lesões agudas ou crônicas, considerada eficaz até em pacientes refratários a outros tratamentos, porém, pode ser afetada pela nicotina (Siana, Rex., 1989; Witte, Barbul., 1997; Maderal, Kirsner.,2016).

O tabagismo está associado a um grande impacto em todas as fases da cicatrização de feridas e no micro ambiente do tecido. A nicotina está associada a efeitos tóxicos específicos 
relacionados ao estresse oxidativo induzido pela droga, sendo os mecanismos preocupantes a redução temporáriana perfusão tecidual e oxigenação, comprometimento das funções celulares inflamatórias, mecanismos bactericidas oxidativos, bem como a atenuação de funções celulares, incluindo síntese e deposição de colágeno (Sørensen., 2012).

A interferência da nicotina na inflamação e proliferação é apontada como responsável pela a maior incidência de complicações na cicatrização tanto aguda quanto crônica em fumantes. A cessação do tabagismo pode reverter alguns desses mecanismos, mas não todos, porque muitos dos processos patológicos induzidos pelo tabagismo parece prolongado ou até irreversível, apesar da abstinência da droga (Ahn et al., 2008; Sørensen., 2012; Goltsman et al., 2017).

A nicotina está relacionada a maior risco de complicações pós-operatórias, pela inibição do fluxo de oxigênio para os tecidos em cicatrização (vasoconstrição), além de elevação dos níveis de carboxihemoglobina no sangue, resultando igualmente em menor tensão de oxigênio nos tecidos (Goltsman et al., 2017; Dinos et al, 2015). Compromete a viabilidade de retalhos e enxertos, apontada em estudos que buscam alternativas para reduzir os efeitos inerentes a droga (Souza et al, 2019).

A sobrevivência dos enxertos é reduzida quando é transferida para leito receptor comprometido pela nicotina, sendo a propensão à necrose três vezes maior em fumantes (Dinos et al, 2015).

Os resultados não significativos tanto para parâmetros respiratórios quanto para aspectos biomecânicos da pele relacionados a nicotina no presente estudo, também foi observado em estudo recente (Toyoda et al, 2018) que obteve resultado semelhante após análise de banco de dados em escala de propensão, isolando o tabagismo como fator de risco para complicações pós-operatórias em procedimentos cirúrgicos plásticos. O tabagismo foi considerado fator de risco independente para infecção incisional profunda no local da cirurgia, deiscência incisional, 
bem como a necessidade de nova intervenção cirúrgica, e como resultado observaram que as taxas morbidades no local da cirurgia não foram significativamente diferentes.

O volume minuto que avalia a quantidade total de ar novo que entra nas vias respiratórias por minuto, sendo o produto da frequência respiratória pelo volume corrente (Carvalho et al., 2007). No presente estudo, não foi observada diferença entre os grupos, provavelmente a resposta esteja relacionada à fase crônica. Sendo observado valores elevados em pacientes agudos (Kim etal.,2017; Levy, Silva, Morano., 2005), que observaram que a queimadura na fase aguda associada ao uso de tabaco, pode acarretar um incremento da frequência respiratória, elevando assim, o volume minuto e consequentemente, podendo ser um fator indicativo de necessidade de ventilação mecânica artificial.

A frequência respiratória (FR), mensuração do número de incursões respiratórias por minuto, quando está elevada denominada de taquipneia, geralmente é involuntária (Saraiva., 1996). Os resultados de pacientes avaliados apresentaram valores não significativos, diferente dos resultados obtidos que observaram taquipnéia em seus pacientes, povavelmente resultante da fase avaliada, assim como resultado do estudo de Pereira., 2002, que aponta a taquipnéia decorrente da restrição gerada pelo curativo oclusivo dos movimentos torácicos, e essa elevação da frequência respiratória pode ocasionar aumento do volume minuto (Echenique et al., 2013).

Geralmente ocorre fadiga da musculatura respiratória quando a carga imposta de trabalho é extensa (Alves, Najas., 2009). O volume corrente (VT) é o volume pulmonar que representa o volume normal do ar circulado entre uma inalação e exalação normal, sem um esforço suplementar. No presente estudo, os valores obtidos da variável nos grupos de pacientes analisados não foram significativos. É provável que este achado esteja relacionado a ausência de dor, aspecto observado no estudo de Echenique et al., 2013 que demonstrou a redução do VT podendo ser resultante da restrição torácica imposta pela dor e pela própria queimadura, acarretando uma diminuição da força muscular e dos volumes pulmonares gerando áreas de 
colapso pulmonar. Rennekampff et al., 2006, também não encontraram correlação de alterações no padrão respiratório dos pacientes avaliados.

Nesse estudo as pressões respiratórias máximas Pimáx e a Pemáx nos pacientes analisados não foram significativos e podem apresentar relação com o índice de massa corporal (Alcântara et al., 2012).Os pacientes apresentaram valores situados em sobrepeso e uma porcentagem desses pacientes com o índice de massa corpórea na faixa da magreza, segundo dados da Organização Mundial da Saúde. Estudo de Silva et al., 2000 aponta que as anormalidades do IMC podem levar a um aumento do trabalho respiratório, ocasionando assim, um déficit da musculatura respiratória, provavelmente não observado pela semelhança de IMC entre osgrupos.

Ferramentas objetivas de medição de parâmetros biomecânicos de cicatrizes permitem a avaliação precisa e reproduzível das cicatrizes, o que é importante para uso clínico e científico (McCalmont., 2013, Lee et al., 2016).

A maleabilidade da pele no presente estudo foi avaliada pelo cutômetro (Cutometer®), instrumento que avalia as propriedades biomecânicas da pele (Sín, Stupka, Brychta., 2010), e a firmeza pelo durômetro (Durometer) que avalia a induração da pele (Falanga, Bucalo., 1993), não sendo encontrada diferença significativa entre os grupos.

É provável que a qualidadeda intervenção terapêutica padrão a que todos pacientes queimados foram submetidos, tenha minimizado o efeito deletério da nicotina na fase aguda da cicatrização, com reflexos diretos na fase crônica. Além disso, outros fatores podem exercer influência nos parâmetros avaliados (Guo, DiPietro., 2010). Estudos adicionais envolvendo indivíduos com maior área de acometimento do tronco por queimaduras, bem como na fase aguda da lesão são necessários, visto que a hipótese deste estudo não foi confirmada com a população avaliada. 
CONCLUSÃO 


\section{CONCLUSÃO}

No presente estudo a influência da cicatriz de tórax no paciente queimado na fase crônica não apresentou alterações significativas na expansibilidade torácica. A maleabilidade e a firmeza e dos tecidos cicatriciais não foram afetadas de forma relevantes. Em relação a expansibilidade pulmonar, os pacientes não apresentaram dor durante a técnica utilizada. Quando comparado a maleabilidade tecidual com a área cicatrical e a expansibilidade pulmonar, os pacientes avaliados não apresentaram diferenças estatísticas consideráveis.

Não foram encontradas diferenças significativas entre indivíduos tabagistas e não tabagistas nos parâmetros respiratórios e biomecânicos da pele na população avaliada. 
REFERÊNCIAS 


\section{REFERÊNCIAS}

Ahn C, Mulligan P, Salcido R. Smoking-the bane of wound healing: biomedical interventions and social influences. ADV Skin Wound Care. 2008;21:227-36.

Alves TK, Najas C. A importância da musculatura respiratória no processo de desmame em pacientes Submetidos a ventilação. Rev. Bras. Queimaduras. 2009;8(3):110-4.

Aköz T, Akan M, Yildirim S. If tou continue to smoke, we may have a problem: smoking's effects on plastic surgery. Aesthetic Plast Surg. 2002 Nov-Dec;26(6):477-82.

Alcântara EC, Silva JDO. Adaptador bocal: um velho conhecido e tão pouco explorado nas medidas da função pulmonar. Assobrafir. Ciência. 2012 Dez;3(3): 43-53.

Angrigiani C, Artero G, Castro G, Khouri Jr B. Reconstruction of thoracic burn sequelae by scar release and flap resurfacing. Burns. 2015;41(8):1877-82.

Bessa EJC, Lopes AJ, Ruffino R. A importância da força muscular respiratória na prática da pneumologia. Pulmão RJ 2014;23(3):37-41

Brewin MP, Lister TS. Prevention or treatment of hypertrophic burn scarring: a review of when and how to treat with the pulsed dye laser. Burns. 2014 Aug;40(5):797-804.

Brusselaers N, Pirayesh A, Hoeksema H, et al: Burn scar assessment: A systematic review of objective scar assessment tools. Burns. 2010;36:1157-1164.

Cavichio BV, Pompeo DC, Oller GASAO, Rossi LA. Tempo de cessação do tabagismo para a prevenção de complicações na cicatrização de feridas cirúrgicas. Rev Esc Enferm USP 2014; 48(1):174-80.

Caldeira VS, Starling CCD, Brito RR, Martins JA, Sampaio RF, Parreira VF. Precisão e acurácia da cirtometria em adultos saudáveis. J Bras Pneumol. 2007;33(5):519-526.

Carvalho CRR, Junior CT , Franca SA.Ventilação mecânica: princípios, análise gráfica e modalidades ventilatórias. Jornal Bras. Pneumol.2007:v.33n.3,p.54-70.

Carswell L, Borger J. Hypertrophic Scarring Keloids. [Updated 2020 Jan 8]. In: StatPearls [Internet]. Treasure Island (FL): StatPearls Publishing; 2020 Jan-. Available from: https://www.ncbi.nlm.nih.gov/books/NBK537058/

Dinos ME, Borke JL, Swiec GD, McPheron JC, Goodin JL, Chuang AH. In vitro study of the adverse effects of nicotine and physical strain on human gingival fibroblasts as a model of the healing of wounds commonly found in the military. Mil Med. 2015 Mar;180(3):86-91

Echenique IA, Chan PA, Chapin KC, Andrea SB, Fava JL, Mermel LA. Clinical characteristics and outcomes in hospitalized patients with respiratory viral co-infection during the 2009 H1N1 influenzapandemic. Jornal Pone. 2013;8(4):60845. 
Falanga V, Bucalo B. Use of a durometer to assess skin hardness. Journal of the AmericanAcademy of Dermatology.1993;29(1):47-51.

Ferreira E, Lucas R, Rossi LA, Andrade D. Dressing of burned patients wounds: a literature review. Rev Esc Enferm USP. 2003;37(1):44-51.

Goltsman D, Munabi NC, Ascherman JA. The Association between Smoking and Plastic Surgery Outcomes in 40,465 Patients: An Analysis of the American College of Surgeons National Surgical Quality Improvement Program Data Sets. Plast Reconstr Surg. 2017;139(2):503-511.

Guo S, DiPietro LA Factors Affecting Wound HealingJ Dent Res. 2010 Mar; 89(3): 219-229.

Held M, Rahmanian-Schwarz A, Rothenberger J, et al. Alteration of biomechanical properties of burned skin. Burns.2015;41(4):789-95.

Kollias S, Stampolidis N, Castana O. Abdominal compartment syndrome (ACS) in a severely burned patiente. Ann burns Fire Disasters. 2015:28(1):5-8.

Jewo PI, Fadeyibe IO. Progress in burns research: A review of advances in burn pathofhysiology. 2015;30;28(2):105-115.

Klinger JR, Abman SH, Gladwin MT. Nitric oxide deficiency and endothelial dysfunction in pulmonary arterial hypertension. Am J Respir Crit Care Med. 2013 Sep. 15;188(6):639-46.

Kim A, Lang T, Xue M, Wijewardana A, Jackson C, Vandervord J. The role of Th-17 cells and $\gamma \delta$ T-Cells in modulating the systemiciInflammatory response to severe burn injury. Int. J. Mol. Sci. 2017:18(4):758.

Lee KC, Dretzke J,Grover L,Logan A, Moiemen N. A systematic review of objective burn scar measurements. Burns Trauma. 2016:7;4-14.

Levy, C. S., Silva, R. M. M. e Morano, M. T. A. P. (2005). O tabagismo e suas implicações pulmonares numa amostra da população em comunidade de fortaleza - CE. Revista Brasileira em Promoção da Saúde, 18(3), 125-129.

Lima OS, Limaverde FS, Filho OSL. Queimados: alterações metabólicas, fisiopatologia, classificação e interseções como tempo de jejum. 2006;91:803-815.

Loguidice MJ, Schutt RC, Horton JW, Minei JP, Keeley EC. Heart rate variability as predictor of death in burn patients. J Burn Care Res. 2016;37(3):227-33.

McCalmont TH. Elasticity. J Cutan Pathol 2013:40:530-531.

Maderal AD, Kirsner RS. Clinical and economic benefits of autologous epidermal grafting. Cureus. 2016 Nov;11:8(11):e875.

Mlcak R, Desai MH, Robinson E, Nichols R, Herndon DN. Lung function following thermal injury in children an 8 year follow up. Burns. 1998;24(3):13-6. 
Pedrini A, Gonçalvez MA, Leal BE, Yamaguti WPS, Paulin E. Comparação entreas medidas tóraco- abdominal realizadas em decúbito dorsal e em ortostátismo. 2013;373-378.

Pereira CAC. Espirometria. J Pneumol. 2002;28(supl. 3):S1-8.

Rabello FB, Souza CD, Farina Júnior JA. Update on hypertrophic scar treatment. Clinics. 2014;69(8):565-573.

Rennekampff HO, Rabbels J, Reinhard V, Becker ST, Schaller HE. Comparing the Vancouver Scar Scale with the cutometer in the assessment of donor site wounds treated with various dressings in a randomized trial. Journal of burn care \& research: official publication of the American Burn Association. 2006;27(3):345-51.

Rowan MP, Cancio LC, Elster EA et al. Burn wound healing and treatment: review and advancements Critical Care. 2015;1-12.

Saraiva, RA. Mecânica Respiratória e Controle da Ventilação. Rev Bras Anestesiol. 1996;46:3:164-174.

Santos C; Tibola J ; Marques CMG. Artigo Original Tradução ,revalidação e confiabilidadeda Escala de Cicatrização de Vancouver para língua portuguesa-Brasil Translation,revalidation andre liability of the Vancouver Scar Scale to Portuguese Language -Brazil-Brazil. Rev. Bras. de Queimaduras. 2014;13(1):26-30.

Santos GP; Freitas NA; Bastos VD; Carvalho FF. Perfil epidemiológico do adulto internado em um centro de referência em tratamento de queimaduras. Rev. Bras. de Queimaduras. 2017;16(2):81-86.

Souza TR, de Souza AK, das Neves LM, Garcia SB, Barbosa RI, Guirro RRJ, Guirro ECO. Photobiomodulation Increases Viability in Full-Thickness Grafts in Rats Submitted to Nicotine. Lasers in Surg and Medicine; 2019. doi: 10.1002/1sm.23155. [Epub ahead of print]

Spanholtz TA, Theodoro P, Amini P, Spilker G. Severe burn injuries: acute andlong-term treatment. Dtsch Arzteli Int. 2009;(106) (38):607-613.

Chua AWC, Khoo YC, Chong SJ. Skin tissue engineering advances in severe burn: review and therapeutic applications. Burns trauma. 2016:4:3.

Pluvy I, Garrido I, Pauchot J, Saboye J, Chavoin JP, Tropet Y, Grolleau JL, Chaput B. Smoking and plastic surgery, part I. Pathophysioological aspects: update and proposed recommendations. Ann Chir Plast Esthet. 2015 Feb;60 (1):3-13.

Sørensen LT, Karlsmark T, Gottrup F. Abstinence from smoking reduces incisional wound infection: a randomized controlled Trial. Ann Surg. 2003;238(1):1-5.

Sørensen LT. Wound healing and infection in surgery: the pathophysiological impact of smoking, smoking cessation, and nicotine replacement therapy: a systematic review. Ann Surg. 2012;255(6):1069-1079. 
Siana JE; Rex S; Gottrup F. The effect of cigarette smoking on wound realing: Scand J Plast Reconstr Surq Hand Surq. 1989:23(3):207-9.

Silverstein P. Smoking and wound healing. Am J Med 1992;93(1A):22S-24S.

Sín P, Stupka I, Brytcha P. Evalution and comparisonof composit and split- thickness skin grafts using cutometer MPA580. Annals of Burn And Fire Disasters. 2010; 33(4):208-213.

Souza AK, Souza TR, Siqueira das Neves LM, Effect of High Voltage Pulsed Current on the integration of total skin grafts in rats submitted to nicotine action. J Tissue Viability. 2019 Aug;28(3):161-166.

Tsukahara K, Takema Y, Moriwaki S, Fujïmura T, Imokawa L. Dermal fluid translocations is an important determinant of the diurnal variation in human skin thickeness. Br J Dermatol. 2001 Out;145(4):590-6.

Toyoda Y,Fu RH,Li L,Otterburn DM,Rohde CH. Smoking as an independent risk factor for postoperative complications in plastic surgical procedures: a propensity score-matched analysis of 36,454 Patients from the NSQIP Database from 2005 to 2014. Plast Reconstr Surg. 2018 Jan;141(1):226-236.

Verhaegen PD, Res EM, Van EA, Middelkoop E, Van ZPP. An reliable, non-invasive meansurement tool for anisotropy in mormal skin and scar tissue. Skin Res Techol. 2010 Aug;16(3):325-31.

Young, Trudie; Fowler, Ann. Tratmento de feridas: gerenciamneto da enfermagem nos locais doadores e receptores de enxertos de pele / wound healing: nursing procedures. Nursing (São Paulo). 1998 ago;1(3):18-25.

Xanthoulea S, Deliaert A, Romano A, Rensen SS, Buurman WA, Van der HRR. Nicotine effects on inflammatory and growth factor responses in murine cutaneous wound healing. J. Intimp. 2013 Dec;17(4):1155-64.

Witte MB, Barbul A. General principles of wound healing. Surg Clin North Am. 1997 Jun;77(3):509- 28. 
APÊENDICES 


\title{
APÊNDICE I - TERMO DE CONSENTIMENTO LIVRE E ESCLARECIDO
}

\author{
HOSPITAL DAS CLÍNICAS DA FACULDADE DE MEDICINA \\ DE RIBEIRÃO PRETO UNIVERSIDADE DE SÃO PAULO (USP)
}

\author{
TERMO DE CONSENTIMENTO LIVRE \\ E ESCLARECIDO AOS SUJEITOS DA PESQUISA
}

\section{Pesquisador Responsável: Profa. Dra. Elaine Caldeira de Oliveira Guirro e Roberta Moretti Marçal}

E-mail: ecguirro@fmrp.usp.br Telefone: (16) 3602-4415 / 3602-1140

Telefone do comitê de ética em pesquisa HCRP e FMRP-USP: 3602- 2228

PROMOTOR DA PESQUISA: Faculdade de Medicina de Ribeirão Preto - USP

PROJETO DE PESQUISA: A influência da queimadura cutânea de tronco na fase aguda e crônica, função pulmonar, muscular respiratória e variabilidade da frequência cardíaca em indivíduos tabagistas.

Senhor(a) , você está sendo convidado(a) para participar de uma pesquisa com o nome de“ $\mathrm{A}$ influência da queimadura cutânea de tronco na fase aguda e crônica, função pulmonar, muscular respiratória e variabilidade da frequência cardíaca em indivíduos tabagistas,"coordenada pela Profa. Dra. Elaine C. De O. Guirro. Para que o(a) Senhor(a) possa decidir se gostaria ou não de participar, esclareceremos abaixo detalhes relacionados aos objetivos da pesquisa e a forma como ela será realizada, entretanto, se houver alguma dúvida fique à vontade para esclarecê-la conosco.

O principal objetivo desta pesquisa é avaliar a influência da queimadura de sua pele na sua respiração, nos músculos e nos batimentos do seu coração. Serão efetuadas algumas avaliações com duração de aproximadamente uma hora no total. A elasticidade da região da pele do tronco afetada pela cicatriz decorrente da queimadura será avaliada por dois instrumentos que ao tocar a pele fazem o registro dos dados. A avaliação será efetuada por meio de pressão perpendicular imposta pelos instrumentos no tecido alvo, com repetição de três vezes, com intervalo de 10 segundos entre as mesmas (duração de $15 \mathrm{~min}$ ).

Também será efetuada a medida do seu tronco durante a respiração por meio de uma trena, durante a inspiração e expiração, sendo que este procedimento terá duração aproximada de 10 minutos. Outras medidas respiratórias serão avaliadas por meio de equipamentos portáteis em que serão solicitadas inspiração e expiração máximas, por três vezes, com duração de aproximadamente 15 minutos.

$\mathrm{O}$ registro de sua frequência cardíaca será efetuado por meio de equipamento acoplado ao seu tronco por aproximadamente 15 minutos.

Os pesquisadores asseguram a sua privacidade quanto a sua identidade e aos dados envolvidos relacionados,os quais serão utilizados exclusivamente para fins de estudo.Os procedimentosaserem realizados oferecem baixos riscos, visto que os métodos de avaliação são de uso clinicamente rotineiro, não invasivos e estão fundamentados cientificamente. As avaliações serão interrompidas no caso qualquer intercorrência não prevista seja identificada.

$\mathrm{O}$ projeto não the garante nenhum benefício adicional direto. Esperamos que no futuro, caso nossas hipóteses venham a ser comprovadas e eventuais benefícios possam ser garantidos aos pacientes. No entanto, a sua participação no estudo possibilitará além do acesso aos exames 
diagnósticos que serão realizados, discussão dos seus resultados individualmente com a equipe de pesquisa em um primeiro momento. Após a conclusão do estudo, você será convidado a se reunir novamenteeindividualmentecomaequipe,ondeseráinformadooresultadodosexamesfinais,além de orientações direcionadas para o seucaso.

Não haverá formas de ressarcimento das despesas decorrentes da participação na pesquisa (transporte ou alimentação), uma vez que o atendimento será efetuado durante o período deconsulta rotineira de seguimento na Unidade de Emergência do Hospital das Clínicas (UEHCFMRP/USP).

Asuaparticipaçãonesteestudoévoluntária,eéseudireitodeixardeparticiparquandodesejar, sem que isso cause penalidade ou prejuízo a sua pessoa. $O$ pesquisador também tem o direito de excluir seus dados deste estudo caso não participe de todas as avaliações ou pela não adequação ao objetivo dessetrabalho.

Osprocedimentosdestapesquisaestãodeacordocomasdiretrizesenormasregulamentadoras de pesquisa envolvendo seres humanos atendendo à Resolução nº466/2012, do Conselho Nacional de Saúde do Ministério da Saúde - Brasília/DF. Os pesquisadores asseguram a sua privacidade quanto a sua identidade e aos dados envolvidos com o estudo, os quais serão utilizados exclusivamente para fins deestudo.

$\mathrm{Eu}$, $\mathrm{RG} \mathrm{n}^{\mathrm{o}}$ abaixo assinado, li e entendi todas as informações contidas neste documento. Concordo em participar do estudo "A influência da queimadura cutânea de tronco na fase aguda e crônica, função pulmonar, muscular respiratória e variabilidade da frequência cardíaca em indivíduos tabagistas," coordenado pela Profa. Dra. Elaine C. de O. Guirro. Tenho pleno conhecimento da justificativa, objetivos, benefícios esperados e dos procedimentos a serem executados, bem como da possibilidade de receber esclarecimentos sempre que considerar necessário. Será mantido sigilo quanto à minha identificação. Ao mesmo tempo assumo o compromisso de retornar nos períodos de exames e seguir as recomendações estabelecidas pelos pesquisadores. Também concordo que os dados obtidos ou quaisquer outras informações permaneçam como propriedade exclusiva dos pesquisadores. Dou pleno direito da utilização desses dados e informações para uso no ensino, pesquisa e divulgação científica. Recebi uma cópia deste termo de consentimento livre e esclarecido e me foi dado a oportunidade de ler e esclarecer minhas dúvidas.

Assinatura: Data:

Pesquisadora: Roberta Moretti Marçal - Telefone: (16) 98255-747

Assinatura:

Data: Coordenadora: Profa. Dra. Elaine Caldeira de OliveiraGuirro Telefone: (16) 3315-4585 


\section{APÊNDICE II - FICHA DE AVALIAÇÃO RESPIRATÓRIA NO PACIENTE QUEIMADO}

Nome: Registro:

Idade:

Data da internação:

Data da queimadura:

$1 \frac{1}{1}$

Procedência: Profissão/ocupação:

Peso:

Altura:

Estado civil:

Reside com quem:

Filho(s): ( ) sim ( ) não

IMC:

Local do acidente:

Ambiente: ( ) aberto

( ) fechado

( ) semi aberto

Tipo de acidente:

( ) acidente doméstico

( ) acidente de trabalho ( ) tentativa de suicídio

( ) tentativa de homicídio ( ) outros especificar:

Agente causador da queimadura:

( ) Etanol ( ) líquidoquente ( ) fogo ( ) gasolina

( ) líquido quente ( ) choque elétrico ( ) produto químico ( ) outros especificar:

Inspeção:

Ausculta Pulmonar:

Dados vitais: FC: PA: Sato2: 
Padrão respiratório: apical ( ) diafragmático ( ) misto ( ) Tipo de tórax:

\begin{tabular}{|l|l|l|l|}
\hline Normal: $(\quad)$ & Tonel: $(\quad)$ & Pectus escavatum: $(\quad)$ & Pectus carinatum: $(\quad$ ) \\
\hline
\end{tabular}

Traumas associados: sim ( ) não ( ) especificar:

Uso de tabaco: sim ( ) não ( ) Maços/dia:

Queixa respiratória: sim ( ) não ( ) especificar:

Medicações prévias: sim ( ) não ( ) especificar:

Uso de álcool: sim ( ) não ( ) especificar:

Uso de drogas: $\operatorname{sim}($ ) não ( ) especificar:

Alergia: $\operatorname{sim}($ ) não ( ) especificar:

Tosse: ( ) ineficaz ( ) eficaz ( ) produtiva ( ) improdutiva ( ) irritadiça

Secreção: ( ) fluída ( ) semi espessa ( ) espessa ( ) fuligem ( ) hialina ( ) amarela

( ) esverdeada ( ) sanguinolenta

Lesão térmica direta: $\operatorname{sim}(\quad$ ) não ( )

Lesão por agentes químicos: $\operatorname{sim}(\quad$ ) não ( )

Lesão inalatória: $\operatorname{sim}(\quad$ ) não ( )

Queimadura de vias áreas superiores: $\operatorname{sim}(\quad$ ) não ( )

Queimadura de vibrissas nasais: sim ( ) não ( )

Rouquidão: ( ) sim ( ) não

\begin{tabular}{|l|l|l|}
\hline Cirtometria & Medida Inspiratória & Medida Expiratória \\
\hline Axilar & & \\
\hline Xifóide & & \\
\hline Umbilical & & \\
\hline
\end{tabular}

\begin{tabular}{|l|l|l|l|}
\hline & M1 & M2 & M3 \\
\hline Pimáx & & & \\
\hline Pemáx & & & \\
\hline Peak Flow & & & \\
\hline Snip Text & & & \\
\hline
\end{tabular}

\begin{tabular}{|l|c|}
\hline & Ventilometia \\
\hline VC & \\
\hline VM & \\
\hline FR & \\
\hline CVL & \\
\hline
\end{tabular}


ANEXOS 


\section{PARECER CONSUBSTANCIADO DO CEP}

\section{DADOS DO PROJETO DE PESQUISA}

Título da Pesquisa: INFLUÊNCIA DA QUEIMADURA CUTÂNEA DE TRONCO, FASE AGUDA E CRÔNICA, NA FUNÇÃO PULMONAR, MUSCULAR RESPIRATÓRIA E VARIABILIDADE DA FREQUÊNCIA CARDÍACA EM INDIVÍDUOS TABAGISTAS.

Pesquisador: ROBERTA MORETTI MARÇAL.

Área Temática:

Versão: 2

CAAE: 83413816.9 .0000 .5440

Instituição Proponente: Hospital das Clínicas da Faculdade de Medicina de Ribeirão Preto da USP

Patrocinador Principal: Financiamento Próprio

\section{DADOS DO PARECER}

Número do Parecer: 2.638.439

\section{Apresentação do Projeto:}

\section{Resumo:}

As queimaduras de tronco, na fase aguda e crônica, podem afetar a função pulmonar e cardíaca pela dor,extensão da queimadura, curativo oclusivo, bem como maleabilidade da cicatriz.O objetivo deste estudo é avaliar a influência da queimadura de tronco, fase aguda e crônica, na função pulmonar, muscular respiratória e variabilidade da frequência cardíaca em indivíduos tabagistas. Serão avaliados 80 indivíduos com idade entre 18-75 anos, de ambos os sexos, que apresentam queimadura de segundo grau profundo e terceiro grau na região do tronco,divididos em quatro grupos iguais: indivíduos não tabagistas na fase aguda (GNTA), indivíduos tabagistas na fase aguda (GTA), indivíduos não tabagistas na fase crônica (GNTC), e indivíduos tabagistas fase crônica (GTC). Para tanto, serão avaliadas a extensão da área atingida, dor, características biomecânicas da pele, frequência respiratória (FR), volumecorrente (VC), 
volume minuto (VM) e capacidade vital lenta (CVL), força muscular inspiratória (PImáx), força muscular expiratória (PEmáx), obstrução pulmonar, expansão pulmonar, bem como a variabilidade da frequência cardíaca (VFC). Para análise estatística serão verificadas as pressuposições de normalidade para os dados por meio do teste estatístico de Shapiro-Wilk e de homocedasticidade entre as variâncias utilizando o teste estatístico de Levene. Quanto à significância estatística de normalidade e a homocedasticidade entre as variâncias forem verificadas, serão verificados efeitos dos grupos aplicando-se a Shapiro-Wilk, seguido do teste post hoc de Tukey; e para os dados que não atenderem as exigências dos métodos paramétricos, serão aplicados os testes de Kruskal-Wallis, seguido do teste de Mann-Whitney com correção de Bonferroni. O teste de Wilcoxon será utilizado para analisar a comparação entre os dados pareados. Para verificar o grau de associação entre as variáveis antropométricas e morfológicas será aplicada a correlação de Spearman. Em todas as análises será considerado o nível de significância alfa=5\%. As análises serão processadas em um único pacote estatístico (SPSS versão 14.0, Inc.,USA).

Palavras-chaves: Fisioterapia; Queimaduras; Maleabilidade; Mecânica Respiratória.

\section{Objetivo da Pesquisa:}

\section{Objetivo Primário:}

Avaliar a influência da queimadura cutânea de tronco, na fase aguda e crônica, na função pulmonar, muscular respiratória, e variabilidade da frequência cardíaca em indivíduos tabagistas.

\section{Objetivo Secundário:}

Avaliar a influência da cicatriz de tórax no paciente queimado na fase aguda e crônica, na expansibilidade torácica e na maleabilidade tecidual; Avaliar a intensidade da dor; Avaliar a variabilidade da frequência cardíaca; Correlacionar a maleabilidade e área da cicatriz com a expansibilidade torácica; Correlacionar a frequência cardíaca com a porcentagem de superfície corpórea queimada. 


\section{Avaliação dos Riscos e Benefícios:}

\section{Riscos:}

Os procedimentos a serem realizados com os voluntários, oferecem baixos riscos, visto que os métodos de avaliação são de uso rotineiro e estão fundamentados cientificamente. As avaliações serão interrompidas no caso qualquer intercorrência não prevista seja identificada.

\section{Benefícios:}

O projeto não lhe garante nenhum benefício adicional direto. Esperamos que no futuro, caso nossas hipóteses venham a ser comprovadas, eventuais benefícios possam ser garantidos aos pacientes. No entanto, a sua participação no estudo possibilitará além do acesso aos exames diagnósticos que serão realizados, discussão dos seus resultados individualmente com a equipe de pesquisa em um primeiro momento. Após a conclusão do estudo, você será convidado a ser reunir novamente e individualmente com a equipe, onde será informado o resultado dos exames finais, além de orientações direcionadas para o seu caso.

\section{Comentários e Considerações sobre a Pesquisa:}

\section{Metodologia Proposta:}

Serão convidados a participar deste estudo, 80 voluntários de ambos os sexos com idade entre 18 a 75 anos, sem distinção de raça, classe ou grupo social, atendidos no Hospital das Clínicas Faculdade de Medicina de Ribeirão Preto - Unidade de Emergência - Queimados Universidade de São Paulo (UE/UQ/HCFMR/USP). Para o recrutamento, serão selecionados os pacientes internados e em atendimento ambulatorial na UQ/UE/HCFMRP/USP, com queimaduras de segundo grau profundo e terceiro grau no tronco e com e sem presença de curativo oclusivo. O paciente será convidado a participar do estudo proposto, sendo expostos os objetivos do estudo e os possíveis resultados esperado. Caso o paciente concorde em participar, será solicitada a leitura do Termo de Consentimento Livre e Esclarecido - TCLE (Apêndice1), disponível em 2 vias.Haverá a possibilidade de esclarecimentos de dúvidas e, caso o paciente concorde em participar deste estudo, o pesquisador irá solicitar a assinaturado TCLE. 


\section{Critério de Inclusão:}

Serão incluídas vítimas de queimaduras de segundo grau profundo e terceiro grau na região de tronco, divididos em quatro grupos de 20 voluntários cada; indivíduos não tabagistas na fase aguda (GNTA), indivíduos tabagistas na fase aguda (GTA), indivíduos não tabagistas na fase crônica (GNTC), indivíduos tabagistas fase crônica (GTC) na faixa etária entre 18 e 75 anos, de ambos os sexos. O paciente deverá estar internado ou realizando seguimento ambulatorial na UE/UQHCFMRP,em bom estado de saúde física e mental. A amostra foi calculada com base no estudo de Angrigiani et al. (2015), sendo a variável avaliada a cirtometria na inspiração profunda em indivíduos com queimaduras de tórax com um poder estatístico de $80 \%$ e um erro alfa de 0,05. O programa utilizado foi o State Mate 2 (GraphPad Software ${ }^{\circledR}$ v 2.0 ), resultando em $n=18$ por grupo, considerando-se $n=20$ para compensar possíveis perdas.

\section{Critério de Exclusão:}

Serão excluídos da pesquisa voluntários com menos de dezoito anos, com doenças respiratórias, cardíacas ou deformidades torácicas prévias, como Doença Pulmonar Obstrutiva Crônica, Asma Bronquite, Enfisema Pulmonar, Insuficiência Cardíaca, Insuficiência Cardíaca Congestiva, Doenças de Chagas e Escolioses que possam interferir na avaliação e procedimentos, e os que não aceitarem assinar o Termo de Consentimento Livre e Esclarecido, e os impossibilitados de realizar os testes. 
Considerações sobre os Termos de apresentação obrigatória:

Os termos foram corrigidos.

\section{Recomendações:}

Não há.

\section{Conclusões ou Pendências e Lista de Inadequações:}

Diante do exposto e à luz da Resolução CNS 466/2012, o projeto de pesquisa, assim como o Termo de Consentimento Livre e Esclarecido Versão 02 Data: 23/04/2018, podem ser enquadrados na categoria APROVADO.

\section{Considerações Finais a critério do CEP:}

Projeto Aprovado: Tendo em vista a legislação vigente, devem ser encaminhados ao CEP, relatórios parciais anuais referentes ao andamento da pesquisa e relatório final ao término do trabalho. Qualquer modificação do projeto original deve ser apresentada a este CEP em nova versão, de forma objetiva e com justificativas, para nova apreciação.

Este parecer foi elaborado baseado nos documentos abaixo relacionados:

\begin{tabular}{|l|l|l|l|l|}
\hline \multicolumn{1}{|c|}{ Tipo Documento } & \multicolumn{1}{|c|}{ Arquivo } & \multicolumn{1}{c|}{ Postagem } & \multicolumn{1}{c|}{ Autor } & Situação \\
\hline $\begin{array}{l}\text { Informações Básicas do } \\
\text { Projeto }\end{array}$ & $\begin{array}{l}\text { PB_INFORMACOES_BASI } \\
\text { CAS_DO_PROJETO_81277 } \\
\text { 1.pdf }\end{array}$ & $\begin{array}{l}23 / 04 / 2018 \\
15: 17: 46\end{array}$ & $\begin{array}{l}\text { ROBERTA } \\
\text { MORETTI } \\
\text { MARCAL }\end{array}$ & Aceito \\
\hline $\begin{array}{l}\text { TCLE / Termos de } \\
\text { Assentimento / } \\
\text { Justificativa de Ausência }\end{array}$ & TCLE.doc & $\begin{array}{l}23 / 04 / 2018 \\
15: 16: 21\end{array}$ & $\begin{array}{l}\text { ROBERTA } \\
\text { MORETTI } \\
\text { MARCAL }\end{array}$ & Aceito \\
\hline Outros & Carta.doc & $\begin{array}{l}19 / 04 / 2018 \\
18: 57: 00\end{array}$ & $\begin{array}{l}\text { ROBERTA } \\
\text { MORETTI } \\
\text { MARCAL }\end{array}$ & Aceito \\
\hline Orçamento & Carta_Aprovacao_Orcament & $\begin{array}{l}21 / 02 / 2018 \\
09: 51: 47\end{array}$ & $\begin{array}{l}\text { ROBERTA } \\
\text { MORETTI } \\
\text { MARCAL }\end{array}$ & Aceito \\
\hline Folha de Rosto & o_UPC.pdf & $\begin{array}{l}18 / 12 / 2017 \\
23: 09: 59\end{array}$ & $\begin{array}{l}\text { ROBERTA } \\
\text { MORETTI } \\
\text { MARCAL }\end{array}$ & Aceito \\
\hline $\begin{array}{l}\text { Declaração de Instituição } \\
\text { e Infraestrutura }\end{array}$ & AFRF.pdf & $\begin{array}{l}18 / 12 / 2017 \\
22: 47: 27\end{array}$ & $\begin{array}{l}\text { ROBERTA } \\
\text { MORETTI } \\
\text { MARCAL }\end{array}$ & Aceito \\
\hline
\end{tabular}

Endereço: CAMPUS UNIVERSITÁRIO

Bairro: MONTE ALEGRE CEP: 14.048-900

UF: SP Município: RIBEIRÃO PRETO

Telefone: (16) 3602-2228 Fax: (16) 3633-1144 E-mail: cep@hcrp.usp.br 


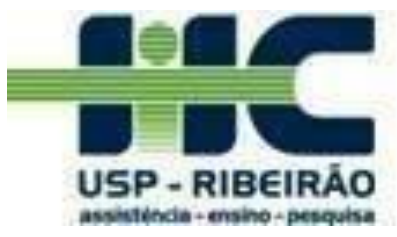

USP - HOSPITAL DAS CLÍNICAS DA

FACULDADE DE MEDICINA DE

RIBEIRÃO PRETO

Platoforma
erafil

\begin{tabular}{|l|l|l|l|l|}
\hline \multicolumn{1}{|c|}{ Tipo Documento } & \multicolumn{1}{c|}{ Arquivo } & \multicolumn{1}{c|}{ Postagem } & \multicolumn{1}{c|}{ Autor } & Situação \\
\hline $\begin{array}{l}\text { Declaração de } \\
\text { Pesquisadores }\end{array}$ & Arquivo4PJ.pdf & $\begin{array}{l}18 / 12 / 2017 \\
22: 46: 48\end{array}$ & $\begin{array}{l}\text { ROBERTA } \\
\text { MORETTI } \\
\text { MARCAL }\end{array}$ & Aceito \\
\hline $\begin{array}{l}\text { Declaração de } \\
\text { Pesquisadores }\end{array}$ & Arquivo2P.pdf & $\begin{array}{l}18 / 12 / 2017 \\
22: 45: 53\end{array}$ & $\begin{array}{l}\text { ROBERTA } \\
\text { MORETTI } \\
\text { MARCAL }\end{array}$ & Aceito \\
\hline $\begin{array}{l}\text { Projeto Detalhado / } \\
\text { Brochura Investigador }\end{array}$ & Projeto.docx & $\begin{array}{l}09 / 11 / 2017 \\
23: 19: 21\end{array}$ & $\begin{array}{l}\text { ROBERTA } \\
\text { MORETTI } \\
\text { MARCAL }\end{array}$ & Aceito \\
\hline
\end{tabular}


Situação do Parecer:

Aprovado

Necessita Apreciação da CONEP:

Não

RIBEIRAO PRETO, 07 de Maio de 2018

Assinado por:

MARCIA GUIMARÃES VILLANOVA

(Coordenador)

Endereço: CAMPUS UNIVERSITÁRIO

Bairro: MONTE ALEGRE CEP: 14.048-900

UF: SP Município: RIBEIRÃO PRETO

Telefone: (16) 3602-2228 $\quad$ Fax: (16) 3633-1144 
HOSPITAL DAS CLÍNICAS DA FACULDADE DE
MEDICINA DE RIBEIRÃO PRETO DA UNIVERSIDADE

DE SÃO PAULO

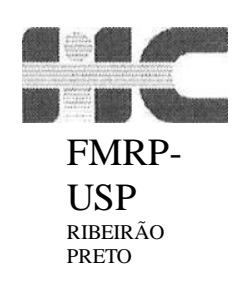

OFICIO N $1238 / 2018$

CEP/MGV

RIBEIRÂO PRETO, 10 DE MAIO DE 2018

PREZADAS SENHORAS,

O TRABALHO INTITULADO "INFLUENNCIA DA QUEIMADURA CUTÂNEA DE TRONCO, FASE AGUDA E CRÔNICA NA FUNÇÃO PULMONAR, MUSCULAR RESPIRATÓRIA E VARIABILIDADE DA FREQUÊNCIA CARDÍACA EM INDIVÍDUOS TABAGISTAS", FOI ANALISADO PELO COMITÉ DE ÉTICA EM PESQUISA EM SUA 46 ${ }^{\underline{a}}$ REUNIÃO ORDINÁRIA, REALIZADA EM 07/05/2018 E ENQUADRADO NA CATEGORIA: APROVADO BEM COMO O TERMO DE CONSENTIMENTO LIVRE E ESCLARECIDO - VERSÂO 2, DE 23/04/2018, DE ACORDO COM O PROCESSO HCRP N 2319/2018.

DE ACORDO COM A CIRCULAR № 003/2011/CONEP/CNS, DATADA DE 21/03/2011, O SUJEITO DE PESQUISA OU SEU REPRESENTANTE, QUANDO FOR O CASO, DEVERÁ RUBRICAR TODAS AS FOLHAS DO TERMO DE CONSENTIMENTO É LIVRE E ESCLARECIDO - TCLE - PONDO SUA ASSINATURA NA ÚLTIMA DO REFERIDO TERMO, O PESQUISADOR RESPONSÁVEL DEVERÁ DA MESMA FORMA, RUBRICAR TODAS AS FOLHAS DO TERMO DE CONSENTIMENTO LIVRE E ESCLARECIDO - TCLE - PONDO SUA ASSINATURA NA ÚLTIMA PÁGINA DO REFERIDO TERMO.

ESTE COMITÊ SEGUE INTEGRALMENTE A CONFERÊNCIA INTERNACIONAL DE HARMONIZAÇÃO DE BOAS PRÁTICAS CLÍNICAS (IGH-GCP), BEM COMO A RESOLUÇÃO X466/12 CNS/MS.

LEMBRAMOS QUE DEVEM SER APRESENTADOS A ESTE CEP, O RELATÓRIO PARCIAL E O RELATÓRIO FINAL DA PESQUISA.

ATENCIOSAMENTE.

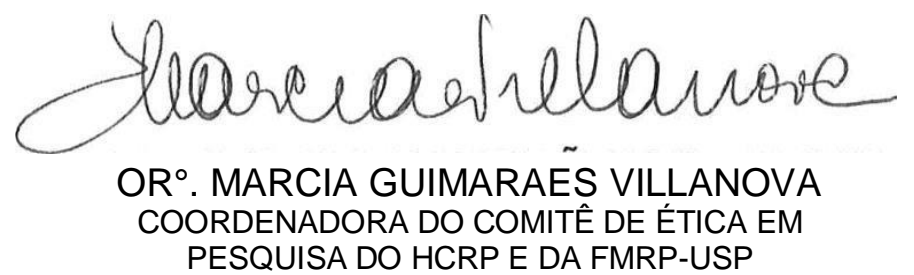

llustríssimas Senhoras

ROBERTA MORETTI MARÇAL

PROF‥ DR ${ }^{\mathrm{a}}$. ELAINE CALDEIRA DE OLIVEIRA GUIRRO (ORIENTADORA)

Depto. de Neurociências e Ciências do Comportamento

HOSPITAL DAS CLÍNICAS DA FACULDADE DE MEDICINA DE RIBEIRÃO PRETO DA UNIVERSIDADE DE SÃO PAULO 